\title{
Efficient synaptic vesicle recycling after intense exocytosis concomitant with the accumulation of non- releasable endosomes at early developmental stages
}

\author{
David Bartolomé-Martín ${ }^{1, *}$, Jorge Ramírez-Franco ${ }^{1, *}$, Enrique Castro ${ }^{2}$, José Sánchez-Prieto ${ }^{1, \ddagger}$ and \\ Magdalena Torres ${ }^{1, \pm}$ \\ ${ }^{1}$ Departamento de Bioquímica, Facultad de Veterinaria, Universidad Complutense, Madrid, 28040, Spain \\ ${ }^{2}$ Departamento de Bioquímica, Biología Molecular y Fisiología, Facultad de Ciencias de la Salud, Universidad de las Palmas de Gran Canaria \\ (ULPG), Las Palmas, Spain \\ *These authors contributed equally to this work \\ †Authors for correspondence (jsprieto@vet.ucm.es; mitorres@vet.ucm.es) \\ Accepted 3 August 2011 \\ Journal of Cell Science 125, 422-434 \\ (c) 2012. Published by The Company of Biologists Ltd \\ doi: $10.1242 / j c s .090878$
}

\section{Summary}

Following the exocytosis of neurotransmitter-containing synaptic vesicles, endocytosis is fundamental to re-establishing conditions for synaptic transmission. As there are distinct endocytotic pathways that each differ in their efficiency to generate releasable synaptic vesicles, we used the dye FM1-43 to track vesicle recycling, and to determine whether nerve terminals use multiple pathways of endocytosis. We identified two types of synaptic boutons in cultured cerebellar granule cells that were characterized by weak or strong FM1-43-unloading profiles. Decreasing the extent of exocytosis dramatically increased the proportion of synaptic boutons that exhibited strong FM1-43-unloading and dramatically reduced the number of endosome-like structures. Hence, we concluded that efficient recycling of synaptic vesicles is concomitant with the formation of non-releasable endosomes in both types of synaptic boutons, although to different extents. Furthermore, cell maturation in culture increased the proportion of synaptic boutons that were capable of an intense release response, whereas the chronic blockage of synaptic activity diminished the capacity of boutons to release dye.

Key words: Cerebellar granule cells, Dynasore, Endocytosis, FM1-43, Synaptic vesicle cycle

\section{Introduction}

Neurotransmission, the principal activity of neurons, involves the fusion of vesicles containing neurotransmitters with the plasma membrane of the nerve terminal. Following their exocytosis, synaptic vesicles are endocytosed and recycled in order to sustain further synaptic transmission. Several forms of endocytosis have been described, including 'kiss-and-run', clathrin-dependent and bulk endocytosis. Kiss-and-run endocytosis involves the transient fusion of synaptic vesicles with the plasma membrane (Valtorta et al., 2001), and, as these vessels do not completely lose their identity (Ceccarelli et al., 1973), they can be rapidly reused after being refilled with a neurotransmitter (Aravanis et al., 2003). During clathrin-dependent exocytosis, vesicles fully collapse before clathrin-mediated invagination and fission occur (Heuser and Reese, 1973; Heuser, 1989). This form of endocytosis is dominant during mild neuronal activity (Granseth et al., 2006). By contrast, strong stimulation provokes bulk endocytosis, which involves large fragments of membrane and the generation of endosome-like structures from which vesicles bud off (Heuser and Reese, 1973; Koenig and Ikeda, 1989; Koenig and Ikeda, 1996; Takei et al., 1996; Teng and Wilkinson, 2000; Richards et al., 2000; Holt et al., 2003; Wu and Wu, 2007). In addition, some forms of endocytosis involve the formation of nonreleasable endososmes that fail to produce secretory vesicles, although the formation of non-releasable endosomes is important in maintaining membrane homeostasis (Perez Bay et al., 2007).
The kiss-and-run mode of endocytosis has been associated with high-frequency stimulation (Zhang et al., 2009), whereas bulk endocytosis also occurs in response to strong stimulation (Wu and Wu, 2007; Clayton et al., 2008; Clayton et al., 2009). However, it remains unclear whether more than one of these vesicle-recycling mechanisms can occur simultaneously within a nerve terminal. FM1-43 is a dye that binds to the lumenal leaflet of synaptic vesicles, from which it is unloaded after subsequent stimulation. Accordingly, FM1-43 can be used to track synaptic vesicle recycling because recycling pathways that are less efficient in delivering fusion-competent vesicles are characterized by a weaker dye loss than the more efficient pathways. Clathrin-mediated endocytosis generates releasable vesicles with a time-constant for the process of around 15 seconds (Granseth et al., 2006; Balaji and Ryan, 2007), which is approximately ten times slower than the kiss-and-run mode of recycling (Gandhi and Stevens, 2003). However, some forms of bulk endocytosis are even less efficient in generating new vesicles (Perez Bay et al., 2007). As distinct endocytotic mechanisms differ in their efficiency of generating releasable vesicles, tracing of the FM1-43 dye can identify the different unloading behaviors when such endocytotic mechanisms coexist within a nerve terminal.

We observed a considerable degree of heterogeneity in the dye unloading by synaptic boutons from cultured cerebellar granule cells. Based on this heterogeneity, we were able to group such synaptic boutons into two subpopulations that were characterized 
by either a weak or a strong loss of FM1-43. Endocytosis in both subsets of nerve terminals was sensitive to the dynamin inhibitor dynasore, which completely prevented dye unloading and dramatically diminished the number of synaptic vesicles. Decreasing the intensity of exocytosis increased the proportion of synaptic boutons that lose large amounts of dye and reduced the presence of endosome-like structures. Together, these findings demonstrate that efficient vesicle-recycling pathways coexist with those pathways that involve the formation of non-releasable endosomes in synaptic boutons, although in different proportions.

\section{Results}

Strong and weak FM1-43-unloading profiles in the synaptic terminals of cerebellar granule cells

To visualize synaptic vesicle recycling, we first determined the ability of cerebellar granule cells to incorporate the fluorescent styryl dye FM1-43 into synaptic vesicles (Fig. 1B) and to unload this dye after stimulation with $50 \mathrm{mM} \mathrm{K}^{+}$(Fig. 1C and see the protocol shown in 1A). FM1-43-fluorescent puncta that were of sufficient quality were initially selected (mask in Fig. 1D), and the synaptic puncta with unfavorable signal-to-noise ratios were excluded (see Materials and Methods). Accordingly, functional synaptic boutons represented $41.4 \pm 9.2 \%$ of the total population in cerebellar granule cells after 7 days in vitro (DIV). The stimulation of cells with $50 \mathrm{mM} \mathrm{K} \mathrm{K}^{+}$produced different kinetic profiles in terms of the rate and extent of dye unloading. To determine the extent of dye release, background-corrected fluorescence for every synaptic bouton was calculated by subtracting the mean background fluorescence of several cellfree regions. The resulting fluorescences were then normalized by dividing by the initial fluorescence in each nerve terminal. The kinetics of dye loss from 20 randomly selected synaptic boutons (Fig. 1E), as well as the unloading frequency histogram of all the synaptic boutons in this same field (791 boutons, Fig. 1F), demonstrated that two subpopulations of synaptic boutons could be distinguished by fitting the data for dye release on to two Gaussian distributions. When the same fit was applied to several fields (Fig. 1G), two Gaussian distributions were obtained, with an intersection value of $42.1 \pm 2.6 \%$. Based on these findings, we assigned nerve terminals that released less than $40 \%$ of their dye as belonging to the weak unloading group, whereas those releasing more than $40 \%$ of the dye were assigned to the strong unloading group. Accordingly, synaptic boutons displayed strong and weak FM1-43 unloading profiles, with a mean dye loss of $52.0 \pm 0.23 \%$ and $34.3 \pm 0.28 \%$, respectively ( \pm s.e.m., $P \leq 0.01$ ANOVA, Fig. $1 \mathrm{H}, \mathrm{I})$. Furthermore, the number of nerve terminals that exhibited strong unloading $(62.6 \pm 4.9 \%)$ outnumbered those with weak unloading $(37.5 \pm 4.9 \%)$. Interestingly, the cumulative probability of the initial FM1-43 fluorescence (prior to unloading) was higher [19.2 \pm 0.8 arbitrary units (a.u.), $n=986$, five fields, $P \leq 0.01$, Kolmogorov-Smirnov $(\mathrm{K}-\mathrm{S})$ test] in synaptic nerve terminals that displayed weak unloading versus those with strong unloading profiles $(14.1 \pm 0.5$ a.u., $n=463$, five fields; Fig. 1J). These differences in the initial FM1-43 uptake might be explained by the less spontaneous release in synaptic boutons with weaker unloading. However, shortening the interval between the loading and unloading steps from 10 minutes to 1 minute in order to reduce spontaneous dye loss did not affect the differences in the initial fluorescence observed between the two groups $(11.6 \pm 0.33$ a.u. and $14.9 \pm 0.52$ a.u. for nerve terminals with strong and weak dye-unloading profiles, respectively). Hence, synaptic boutons with a weak unloading profile take up more dye than those with a strong unloading profile.

Stimulation with $\mathrm{K}^{+}$results in a biphasic unloading profile (Fig. 1I), as observed in other $\mathrm{K}^{+}$-stimulated preparations (Klingauf et al., 1998; Mozhayeva et al., 2002). The initial phase of this pattern can be attributed to the release of dye from a rapidly mobilizable pool of vesicles (in the order of seconds), while the slow phase reflects the replenishment of this rapidly mobilizable vesicle population from the reserve pool (Mozhayeva et al., 2002). Interestingly, when determining the rates of dye release, the data were normalized by subtracting the background fluorescence of the synaptic bouton after stimulation. Synaptic boutons exhibiting a strong dye loss had time-constant values of $9.6 \pm 0.6$ and $91.2 \pm 11.4$ seconds ( $n=1119$, seven fields), whereas the time-constant values of synaptic boutons exhibiting weak dye loss were $16.8 \pm 3.0$ and $113 \pm 23.4$ seconds $(n=669$, seven fields). This indicates that both synaptic bouton populations contain a pool of synaptic vesicles that gives rise to the rapid component of dye release. As dye loading and unloading involve the same stimulation protocol $(50 \mathrm{mM} \mathrm{K}$, 5 minutes), any differences in dye loss between synaptic terminals exhibiting strong and weak unloading profiles might reflect distinct capacities for recycling. Indeed, some loaded vesicles appeared not to recycle completely or render releasable vesicles, indicating that alterations to the endocytotic stage of the vesicle cycle had taken place.

Although the release of neurotransmitter is not linearly dependent on $\mathrm{Ca}^{2+}$, decreasing the extracellular $\mathrm{Ca}^{2+}$ concentrations $\left(\left[\mathrm{Ca}^{2+}\right]_{\mathrm{e}}\right)$ dramatically reduces the probability of release. We investigated whether reducing the extent of exocytosis by decreasing the $\left[\mathrm{Ca}^{2+}\right]_{\mathrm{e}}$ from 1.3 to 0.5 or $0.25 \mathrm{mM}$ during FM1-43 loading affected subsequent dye unloading. The decrease in $\left[\mathrm{Ca}^{2+}\right]_{\mathrm{e}}$ enhanced the proportion of nerve terminals exhibiting strong dye loss $(59.9 \pm 6.3 \%$ at $1.3 \mathrm{mM}$ $\mathrm{CaCl}_{2}$ and $74.1 \pm 10.0 \%$ at $0.5 \mathrm{mM} \quad \mathrm{CaCl}_{2}, P \geq 0.05$; and $87.5 \pm 3.9 \%$ at $0.25 \mathrm{mM} \mathrm{CaCl} 2, \quad P \leq 0.05$, Fig. $2 \mathrm{~A}-\mathrm{C})$. As decreasing the $\left[\mathrm{Ca}^{2+}\right]_{\mathrm{e}}$ did not affect either the proportion of functional boutons $(67.8 \pm 5.1 \%, 63.3 \pm 9.2 \%$ and $60.0 \pm 8.4 \%$ at 1.3 , 0.5 and $0.25 \mathrm{mM} \mathrm{CaCl}_{2}$, respectively; $P \geq 0.05$ ), or their density $(0.055 \pm 0.01, n=4,0.075 \pm 0.002, n=4$ and $0.055 \pm 0.01, n=3$, $P \geq 0.05$ by $t$-test, at $1.3,0.5$ and $0.25 \mathrm{mM} \mathrm{CaCl}_{2}$, respectively), we concluded that reducing the $\left[\mathrm{Ca}^{2+}\right]_{\mathrm{e}}$ decreases the number of nerve terminals with a weak unloading profile. Indeed, reducing the $\left[\mathrm{Ca}^{2+}\right]_{\mathrm{e}}$ slightly increased the mean extent of unloading in both nerve terminal groups (Fig. 2D).

Strong stimulation results in bulk endocytosis of large membrane patches and the generation of endosome-like structures from which vesicles bud off (Heuser and Reese, 1973). As bulk endocytosis involves slower vesicle recycling than clathrin-mediated endocytosis (Perez Bay et al., 2007), it is possible that this mechanism is dominant in weak unloading nerve terminals. Because larger stretches of membrane are exposed to the extracellular medium for longer periods of time during bulk endocytosis compared with clathrin-dependent endocytosis, the law of mass action means that the labeling of vesicles derived from bulk endocytosis should be more resistant to decreases in FM1-43 concentration than vesicles generated through clathrin-dependent endocytosis. Diminishing the concentration of FM1-43 from 10 to 5 or $3 \mu \mathrm{M}$ during the loading period decreased the proportion of nerve terminals 
A

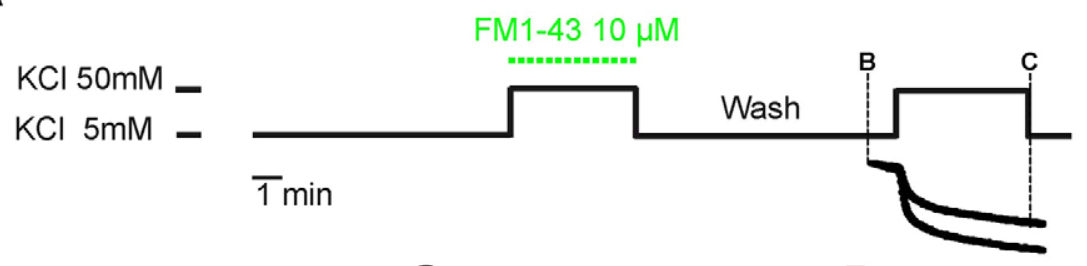

B

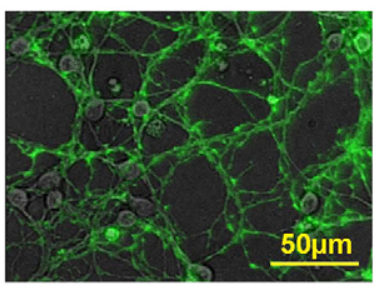

C

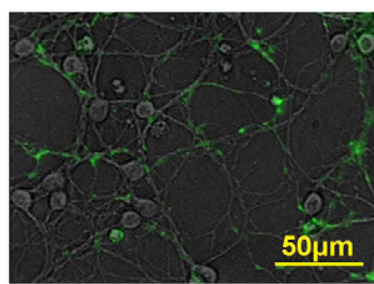

D
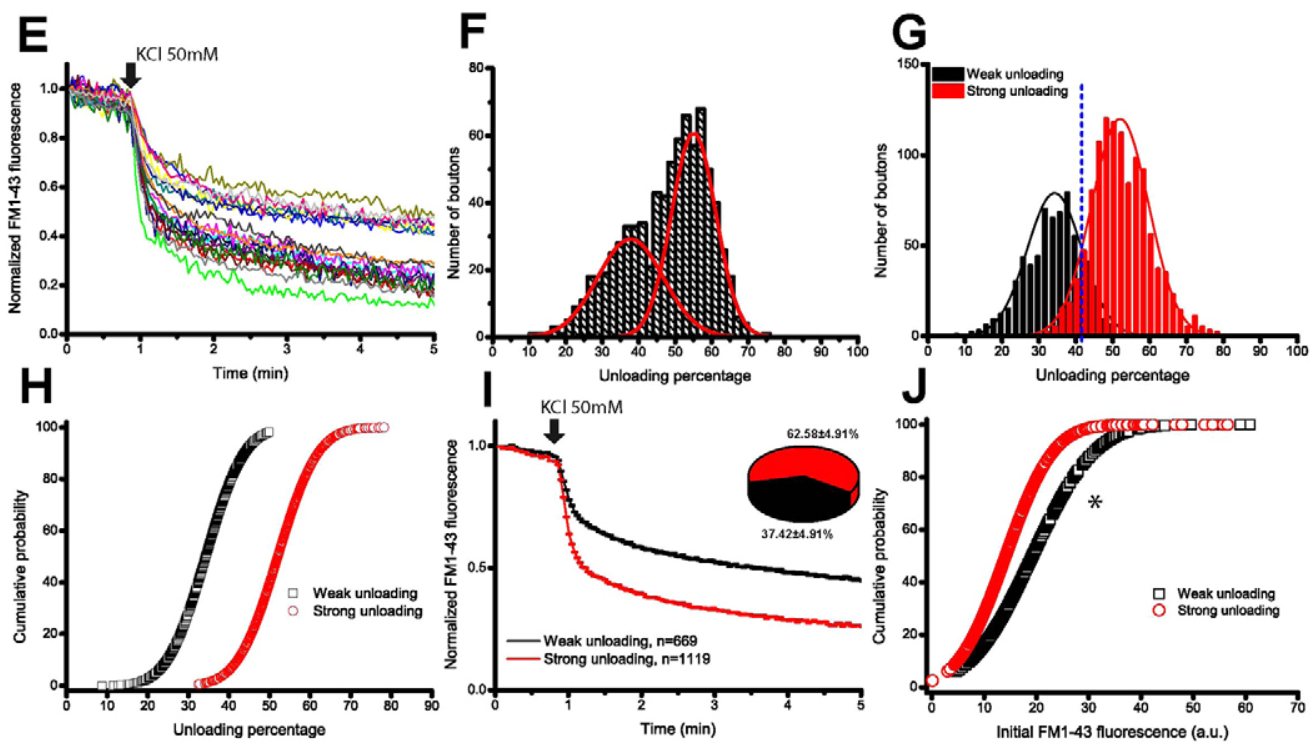

Fig. 1. Two subpopulations of synaptic boutons can be identified in cerebellar granule cells on the basis of their FM1-43 unloading kinetics.

(A) Diagram showing the protocol used for cell loading and unloading. Superimposition of phase-contrast and fluorescence images before (B) and after (C) FM143 unloading with $50 \mathrm{mM} \mathrm{KCl}$. (D) Mask of nerve terminals obtained using Igor Pro software. (E) Kinetics of FM1-43 unloading of 20 randomly selected synaptic boutons during sustained stimulation with $50 \mathrm{mM} \mathrm{KCl}$. (F) Frequency histogram showing the percentage of FM1-43 unloading for the 791 synaptic boutons in the field after a 2 minute stimulation. Data are fitted to a two-peak distribution. (G) Frequency histogram of FM1-43 unloading (1788 synaptic terminals from seven fields) reveals a two-peak distribution. The dotted blue line indicates the intersection value of the two Gaussian curves. (H) Cumulative probability plots of FM1-43 unloading in synaptic boutons with strong and mild FM1-43 unloading. (I) Average unloading kinetics of nerve terminals with strong ( $n=1119$, seven fields) and mild FM1-43 dye loss ( $n=669$, seven fields). Inserted disc diagram shows the percentage of nerve terminals with strong and weak FM1-43 unloading kinetics (the data represent the unloading \pm s.e.m.). (J) Cumulative probability of the initial FM1-43 fluorescence measured before unloading with $50 \mathrm{mM} \mathrm{KCl}$ $[P \leq 0.01$ when compared with initial FM1-43 fluorescence values (a.u.) between the two groups of nerve terminals; Kolmogorov-Smirnov test].

showing a strong dye loss and increased the proportion of nerve terminals exhibiting a weak dye loss $(73.9 \pm 7.6 \%$ and $26.1 \pm 7.6 \%$ at $10 \mu \mathrm{M}$ FM1 $-43 ; 27.9 \pm 3.9 \%$ and $72.1 \pm 3.9 \%$ at $5 \mu \mathrm{M}$ FM1- 43 , $P \leq 0.01 ; 10.3 \pm 6.1 \%$ and $89.7 \pm 6.1 \%$ at $3 \mu \mathrm{M}$ FM1-43, $P \leq 0.001$; Fig. 3A-C). Indeed, decreasing the dye concentration significantly reduced the mean extent of unloading in both groups of nerve terminals (Fig. 3D) and the density of functional boutons $(0.054 \pm 0.01$ at $10 \mu \mathrm{M}$ FM1-43, $0.020 \pm 0.002$ at $5 \mu \mathrm{M}$ FM1-43 and $0.014 \pm 0.0019$ at $3 \mu \mathrm{M}$ FM1-43, $P \leq 0.05$, Fig. 3E). Thus, when the FM1-43 concentration is reduced, nerve terminals that exhibit weak unloading are preferentially labeled.

\section{FM1-43 loading after stimulation preferentially labels synaptic boutons that exhibit a weak unloading profile}

The stronger initial fluorescence that was observed in synaptic boutons with a weak unloading profile was not explained by differences in the rate of spontaneous release. Indeed, shortening or lengthening the interval between loading and unloading steps did not alter such rates, suggesting that these boutons take up more dye. To test the possibility that nerve terminals with weak unloading profiles contain structures that remain exposed to the extracellular medium for longer, cells were stimulated with $50 \mathrm{mM} \mathrm{K}^{+}$in the absence of FM1-43 and then exposed to the 

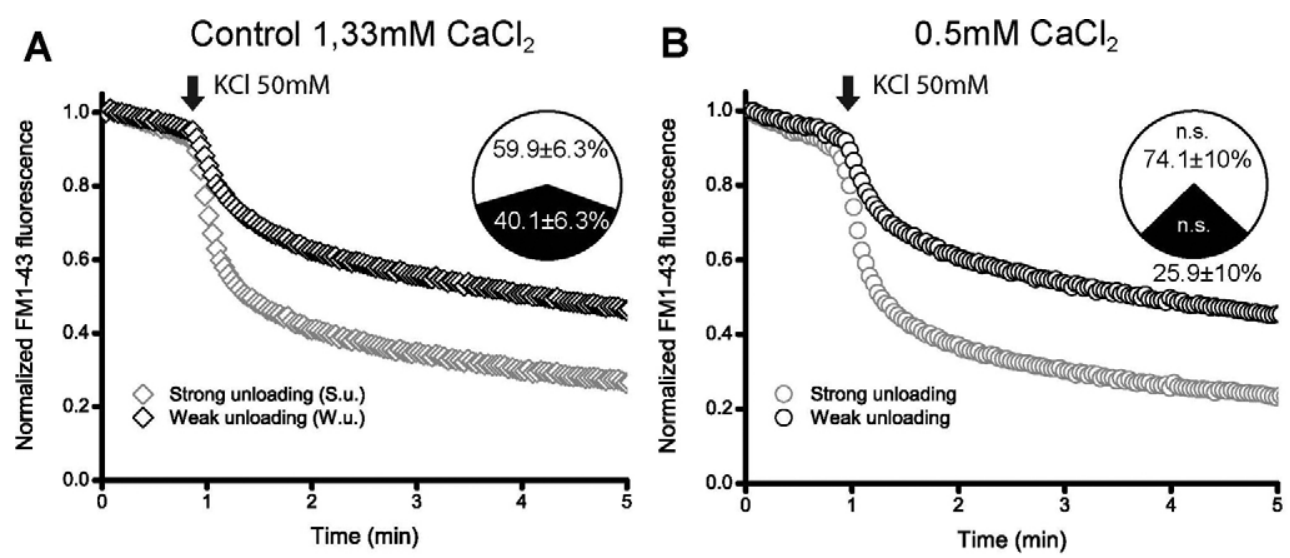

Fig. 2. Decreasing extracellular $\mathrm{Ca}^{2+}$ concentration during FM1-43 loading reduces the proportion of nerve terminals exhibiting a weak dyeunloading profile. Average unloading kinetics of synaptic boutons with strong and weak unloading profiles at extracellular $\mathrm{Ca}^{2+}$ concentrations of $1.3 \mathrm{mM} \mathrm{CaCl}_{2}(n=1209$, five fields; A), $0.5 \mathrm{mM} \mathrm{CaCl}_{2}(n=1410$, four fields; B) and $0.25 \mathrm{mM} \mathrm{CaCl}_{2}(n=1188$, four fields; C). Inserted pie charts indicate the percentage of nerve terminals with strong and weak FM1-43 unloading.
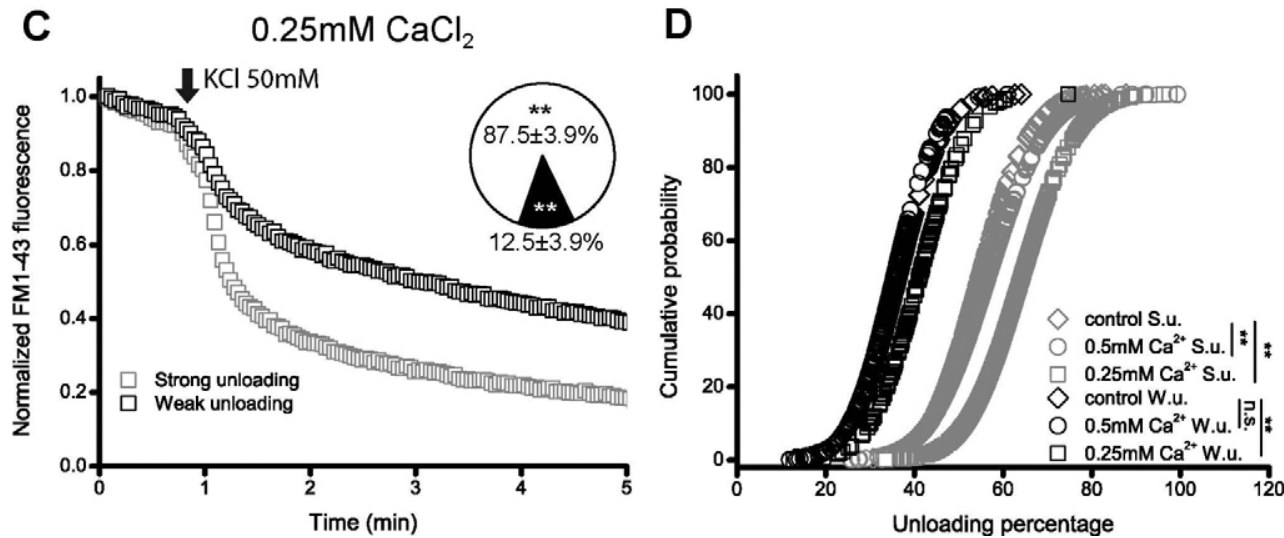

(D) Cumulative probability plots of FM143 unloading of synaptic boutons with strong and mild FM1-43 unloading profiles. The mean percentage of dye unloading of synaptic boutons with strong and weak FM1-43 unloading profiles was: $55.0 \pm 0.3 \%$ and $36.1 \pm 0.3 \%$ at $1.3 \mathrm{mM}$ $\mathrm{CaCl}_{2} ; 56.7 \pm 0.3 \%$ and $35.3 \pm 0.4 \%$ at $0.5 \mathrm{mM} \mathrm{CaCl}_{2}$; and $64.2 \pm 0.3 \%$ and $41.1 \pm 0.7 \%$ at $0.25 \mathrm{mM} \mathrm{CaCl}_{2}, P \leq 0.001$ ANOVA. The data represent the mean \pm s.e.m. and n.s. $(P \geq 0.05)$ determined by $t$ tests in comparison with values at $1.3 \mathrm{mM} \mathrm{CaCl}_{2}$.

probe immediately after stimulation (Fig. 4C). When the unloading kinetics of these cells were analyzed with $50 \mathrm{mM} \mathrm{K}$ after washing, the dye preferentially labeled synaptic terminals with weak unloading profile conditions $(76.9 \pm 6.0 \%$ compared with $38.5 .2 \pm 4.8 \%$ when loaded under standard conditions, $P \leq 0.01$, Fig. 4A,B,D). Moreover, fewer synaptic boutons were labeled by using this protocol (Fig. 4C), as indicated by the decrease in bouton density (Fig. 4E). Hence, it seems possible that the endosome-like structures at nerve terminals with weak unloading profiles remain exposed to the extracellular medium for longer.

\section{Synaptic vesicle recycling is fully dependent on dynamin} Dynasore is a dynamin GTPase inhibitor known to block clathrindependent endocytosis (Macia et al., 2006; Newton et al., 2006; Kirchhausen et al., 2008). Exposure of the synaptic vesicles to dynasore $(20 \mu \mathrm{M})$ for 30 minutes prevented $\mathrm{KCl}$-induced FM1-43 unloading from both types of nerve terminals (Fig. 5C), indicating that, in this case, FM1-43 unloading was dynamin dependent. In addition, we found that dynasore dramatically reduced the number of labeled puncta (Fig. 5A,C) and the initial fluorescence of the labeled synaptic boutons (Fig. 5D). Indeed, dynasore-resistant FM1-43 labeling was almost completely suppressed by decreasing the $\left[\mathrm{Ca}^{2+}\right]_{\mathrm{e}}$ to $0.25 \mathrm{mM}$ (compare Fig. $5 \mathrm{~B}, \mathrm{C}$ with $5 \mathrm{~A}, \mathrm{C}$ ). As decreasing the $\left[\mathrm{Ca}^{2+}\right]_{\mathrm{e}}$ dramatically reduced the proportion of nerve terminals with weak unloading profiles, these findings indicate that dynamin-independent FM1-43 labeling did not substantially contribute to synaptic vesicle recycling, at least under our experimental conditions. However, the coexistence of dynamin-independent and dynamin-dependent endocytosis within synaptic boutons reflects the overall efficiency of synaptic vesicle recycling. As such, synaptic boutons with a lower proportion of dynamin-independent endocytosis recycle synaptic vesicles very efficiently, as witnessed by the more extensive FM1-43 unloading. By contrast, boutons with a higher proportion of dynaminindependent endocytosis exhibit weaker FM-1-43 unloading. To elucidate further the molecular mechanisms sustaining the two forms of recycling, we used dynamin inhibitors other than dynasore. Accordingly, we used tetradecyltrimethylammonium bromide (MiTMAB) as an inhibitor of dynamin-1 and -2, which competes with phosphatidylserine for the pleckstrin-homology domain. We found that MiTMAB ( $5 \mu \mathrm{M}, 10$ minutes) almost completely prevented FM1-43 labeling (supplementary material Fig. S1A,C,D,E). The detergent effect of MiTMAB under our experimental conditions prevented the use of higher concentrations. In addition, the low level of uptake of FM1-43 in MiTMAB experiments resulted in noisy traces that prevented further analysis of the unloading kinetics (supplementary material Fig. S1B). Then, dynamin-dependent mechanisms seem to be responsible for the effective recycling of synaptic vesicles, thus providing new competent vesicles that are able to sustain consecutive rounds of exocytosis.

\section{The calcineurin inhibitor FK-506 impairs synaptic vesicle recycling}

In addition to initiating exocytosis, elevating $\mathrm{Ca}^{2+}$ levels at nerve terminals activates the protein phosphatase calcineurin, resulting 
A

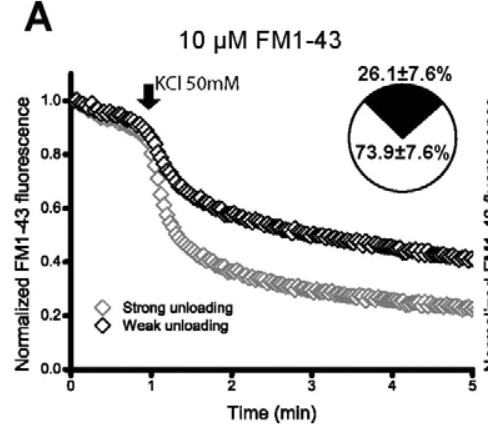

D

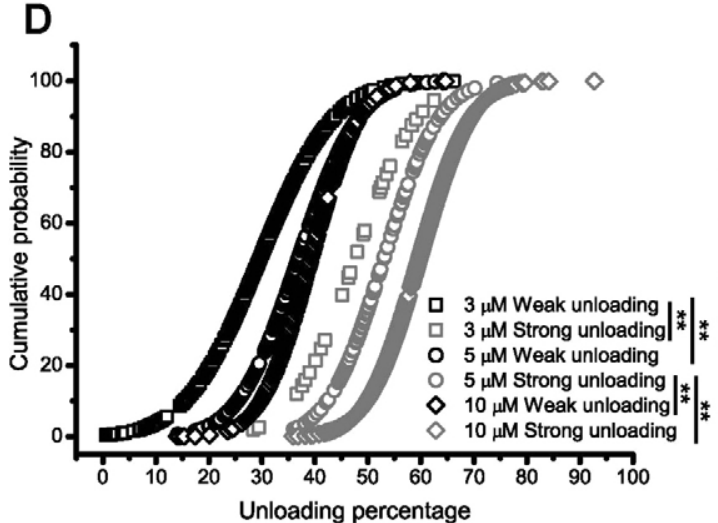

B

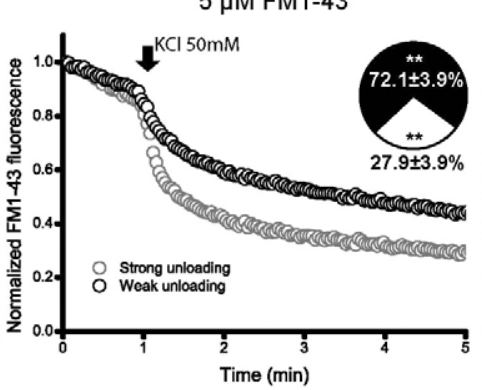

C

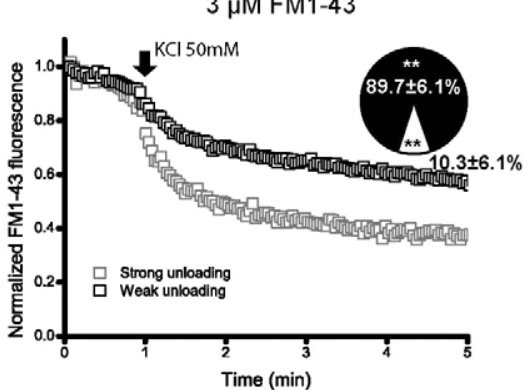

E

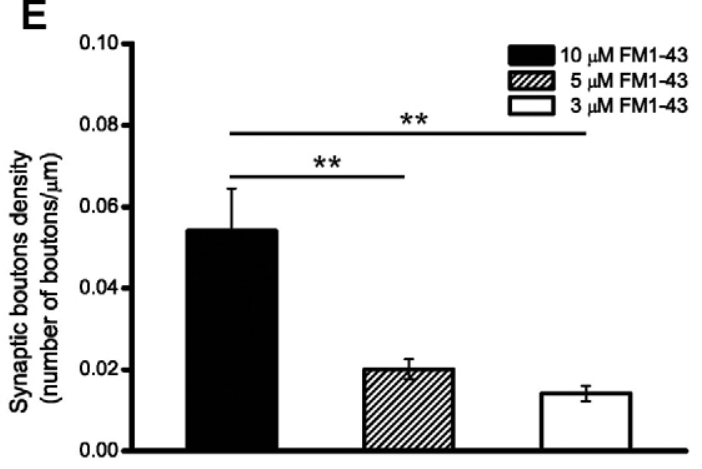

Fig. 3. Decreasing the FM1-43 concentration reduces the proportion of nerve terminals exhibiting a strong dye-unloading profile. Average unloading kinetics of synaptic boutons with strong and weak unloading profiles at $10 \mu \mathrm{M}(n=1394$, four fields; A), $5 \mu \mathrm{M}(n=417$, four fields; B) and $3 \mu \mathrm{M}$ FM1-43 ( $n=375$, four fields; C) in cerebellar granule cells at 8 DIV. Inserted pie charts indicate the percentage of nerve terminals exhibiting strong and weak dye loss. (D) Cumulative probability plots of FM1-43 unloading of nerve terminals with strong and weak dye loss. The mean percentage of unloading of synaptic boutons was: $59.7 \pm 0.2 \%$ and $39.2 \pm 0.1 \%$ at $10 \mu \mathrm{M} \mathrm{FM} 1-43 ; 53.0 \pm 0.7 \%$ and $36.9 \pm 0.53 \%$ at $5 \mu \mathrm{M} \mathrm{FM} 1-43(P \leq 0.001$, ANOVA); and $47.5 \pm 1.8 \%$ and $29.6 \pm 0.6 \%$ at $3 \mu \mathrm{M}$ FM1-43 ( $P \leq 0.001$, ANOVA), for nerve terminals with strong and weak FM1-43 unloading, respectively. (E) Bouton density (number of functional boutons/ $\mu \mathrm{m})$ at different FM1-43 concentrations. The data represent the mean \pm s.e.m. and $* * P \leq 0.01$ when compared with values at $10 \mu \mathrm{M}$ FM1-43 ( $t$-test).

in the subsequent dephosphorylation and/or activation of a number of presynaptic proteins involved in vesicle recycling, including dynamin, amphiphysin and synaptojanin. Indeed, clathrin-mediated endocytosis is a calcineurin-dependent process (Clayton and Cousin, 2009). Hence, we used the calcineurin inhibitor FK-506 to determine whether vesicle recycling at nerve terminals was influenced by calcineurin. Accordingly, FK-506 ( $1 \mu \mathrm{M}$, added 35 minutes prior to loading and maintained during FM1-43 loading) dramatically altered nerve-terminal unloading, decreasing the proportion of synaptic boutons with a strong dye-unloading profile to $24.4 \pm 2.8 \%$ $(P \leq 0.01)$ from the $71.5 \pm 7.8 \%$ observed under control conditions (Fig. 5E,F). FK-506 also reduced the overall mean unloading of functional nerve terminals, indicating that synaptic vesicle recycling is largely dependent on calcineurin. However, the density of functional boutons remained unaffected by the presence of this inhibitor (control: $0.04 \pm 0.004, n=4$; FK-506: $0.04 \pm 0.002, n=6 ; P>0.05)$.

\section{Intensive exocytosis triggers the formation of large endosomes}

To test directly whether endosome-like structures are present in nerve terminals with weak dye-unloading profiles, we analyzed cell cultures by electron microscopy under the following distinct conditions: (1) control resting conditions, in which the cells were unstimulated (5 $\left.\mathrm{mM} \mathrm{K}^{+}\right)$; (2) control conditions stimulated with physiological concentrations of $\mathrm{Ca}^{2+}\left(50 \mathrm{mM} \mathrm{K}^{+}, 1.3 \mathrm{mM} \mathrm{Ca}^{2+}\right)$, in which the nerve terminals with strong unloading profiles outnumbered those with weak unloading profiles; (3) control conditions stimulated with low concentrations of $\mathrm{Ca}^{2+}(50 \mathrm{mM}$ $\mathrm{K}^{+}, 0.25 \mathrm{mM} \mathrm{Ca}^{2+}$ ), in which most of the nerve terminals exhibited strong unloading profiles; (4) in the presence of the dynamin inhibitor dynasore, under resting conditions; (5) in the presence of dynasore while being stimulated with physiological concentrations of $\mathrm{Ca}^{2+}$, which mostly stimulates weak dye loss; (6) in the presence of dynasore while being stimulated with low concentrations of $\mathrm{Ca}^{2+}$, which results in the complete loss of nerve terminal labeling. The stimulated cells were treated with (50 $\mathrm{mM} \mathrm{K}^{+}$for 2 minutes) to mimic the loading step and were then washed. The average number of organelles (small synaptic vesicles of diameter $<40 \mathrm{~nm}$ and large vesicles $>40 \mathrm{~nm}$ ) per synaptic terminal was assessed for each condition by estimating the number of organelles in 15-22 nerve terminals. The nerve terminals of control cells in resting conditions contained small synaptic vesicles $(35.0 \pm 7.0)$, whereas large structures were virtually absent $(0.4 \pm 0.1$; Fig $6 \mathrm{~A}, \mathrm{~B})$. Control cells that were stimulated with physiological concentrations of $\mathrm{Ca}^{2+}$ contained both small synaptic vesicles $(22.0 \pm 5.0$ per terminal $)$ and larger structures (5.0 \pm 1.0 per terminal; Fig. 6C,D), which is consistent with the coexistence of clathrin-dependent endocytosis and bulk endocytosis. Lowering the $\left[\mathrm{Ca}^{2+}\right]_{\mathrm{e}}$ abolished the large structures $(0.6 \pm 0.2$ per terminal, $P \leq 0.01)$ and slightly increased the number 

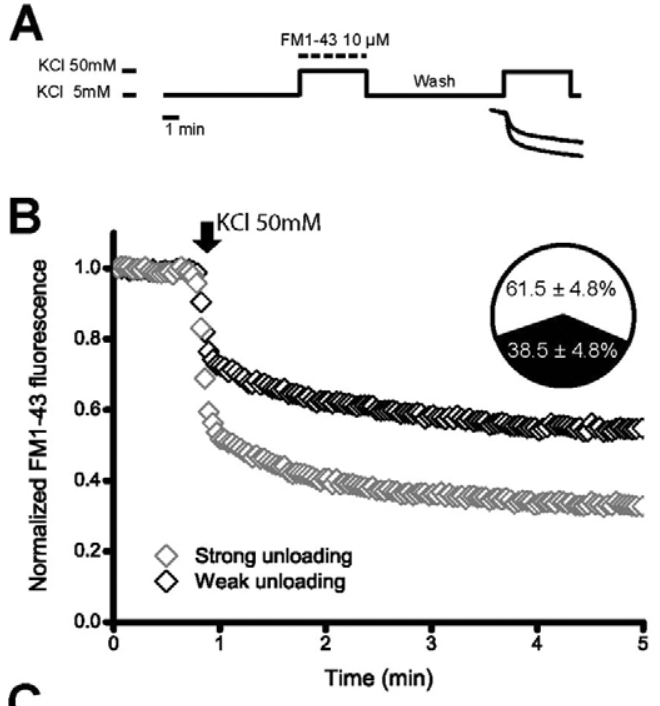

C

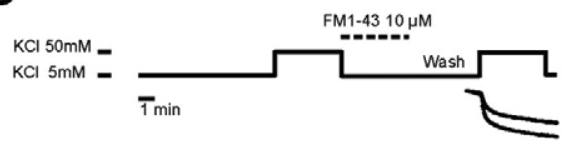

D

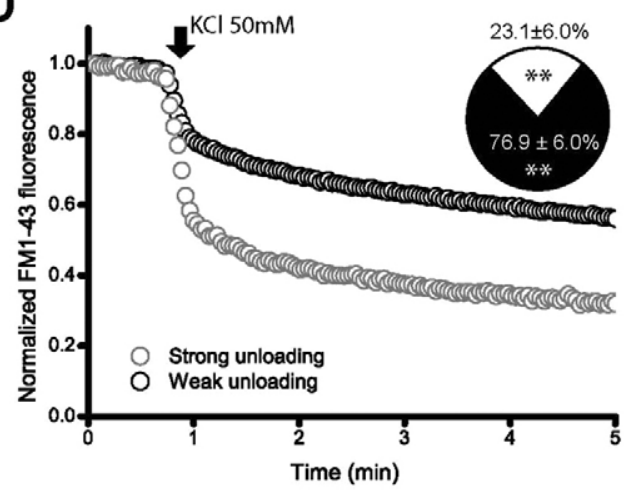

E

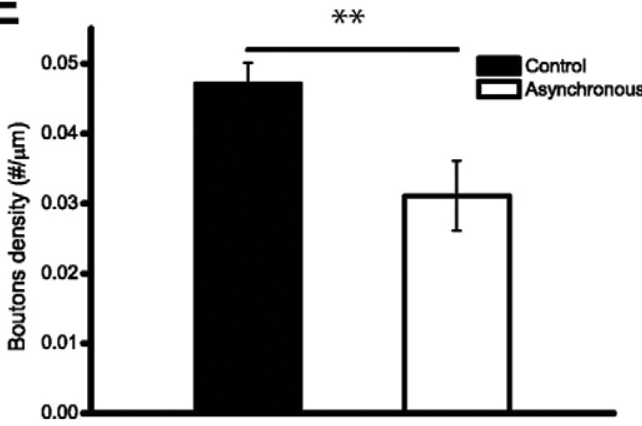

Fig. 4. FM1-43 uptake at nerve terminals after stimulation with $\mathrm{K}^{+}$. (A-D) Protocol used for standard (A) and asynchronous (C) FM1-43 loading of cerebellar granule cells. Average unloading kinetics of nerve terminals with strong and weak dye-unloading profiles under standard ( $n=174$, two fields; B) and asynchronous ( $n=386$, four fields; D) loading conditions. Inserted pie chart shows the percentage of nerve terminals with strong and weak FM1-43 unloading kinetics. ${ }^{* *} P \leq 0.01$, when compared with the corresponding value under standard loading conditions ( $t$-test). (E) Bouton density (number of functional boutons $/ \mu \mathrm{m}$ ) after control and asynchronous FM1-43 loading. Data represent the mean \pm s.e.m. and $* * P \leq 0.01$ when compared with values under standard loading conditions $(t$-test). of small synaptic vesicles $(33.0 \pm 4.0$ per terminal, $P \geq 0.05$; Fig. 6E,F), which is consistent with the loss of nerve terminals exhibiting weak dye loss. The dynamin inhibitor dynasore blocks clathrin-mediated endocytosis (Newton et al., 2006), and, under resting conditions in the presence of dynasore, the numbers of synaptic vesicles and large structures were $36.0 \pm 6.0$ and $0.3 \pm 0.1$, respectively (Fig. 6G,H). The number of small synaptic vesicles diminished in cells that were stimulated with physiological concentrations of $\mathrm{Ca}^{2+}$ in the presence of dynasore $(7 \pm 2$ per nerve terminal, $P \leq 0.01$ ), whereas recycling through large structures remained unaffected ( $5 \pm 1$ per terminal, $P \geq 0.05$; Fig. $6 \mathrm{I}, \mathrm{J})$. These data further emphasize the fact that endocytosis that is mediated by large structures is ineffective in maintaining the pool of small synaptic vesicles. Finally, decreasing the extent of exocytosis by reducing the $\left[\mathrm{Ca}^{2+}\right]_{\mathrm{e}}$ to $0.25 \mathrm{mM}$ in the presence of dynasore reduced the number of small synaptic vesicles $(10 \pm 2$ per synaptic bouton, $P \leq 0.01)$ - furthermore, vesicle recycling through large structures was abolished $(1 \pm 0$ per terminal, $P \leq 0.01$ : Fig. $6 \mathrm{~K}, \mathrm{~L})$. These data were consistent with the dramatic decrease in FM1-43 loading observed under these conditions and further indicated that FM1-43 labeling in the presence of dynasore is mediated by endosome-like structures.

\section{Cell maturation enhances synaptic protein content and vesicle recycling efficiency}

Weak dye-unloading from synaptic boutons might reflect recycling of immature synaptic vesicles. As such, we determined whether the number of these synaptic boutons was modified as cells matured by assessing FM1-43 unloading kinetics at 3, 7 and 14 DIV. Neuronal cell maturation increased the number of functional synaptic boutons $(24.3 \pm 3.8 \%$, $41.4 \pm 9.2 \%$ and $78.9 \pm 3.5 \%$ at 3,7 and 14 DIV, respectively), and the proportion of nerve terminals exhibiting a strong unloading profile $(50.0 \pm 4.1 \%, 63.9 \pm 7.4 \%$ and $66.2 \pm 3.4 \%$ at 3 , 7 and 14 DIV, respectively, $P \leq 0.05)$, with a corresponding decrease in the proportion of nerve terminals exhibiting a weak unloading profile $(50.0 \pm 0.1,36.1 \pm 7.4$ and $33.8 \pm 3.4$ at 3,7 and 14 DIV, respectively, $P \geq 0.05$, Fig. 7A). Cell maturation did not significantly change the mean extent of dye unloading in terminals displaying strong unloading $(63.9 \pm 1.1 \%, 60.3 \pm 1.8 \%$ and $63.0 \pm 1.1 \%$ at 3 DIV, 7 DIV and 14 DIV, respectively, $P \geq 0.05$, Fig. 7B), whereas a mild yet significant increase in mean FM1-43 unloading was observed in the nerve terminals exhibiting weak dye loss $(35.6 \pm 3.0 \%, 38.7 \pm 1.1 \%$ and $43.3 \pm 0.9 \%$ at 3 DIV, 7 DIV and 14 DIV, respectively, $P \leq 0.05$, Fig. 7B). Finally, as cell cultures matured, there was an increase in the mean initial FM1-43 fluorescence corresponding to both types of nerve terminals, which was consistent with an increase in the size of the synaptic vesicle pools (Mozhayeva et al., 2002). This change persisted at all ages of the cell cultures that were studied (Fig. 7C).

To determine whether the maturation of presynaptic function depends on synaptic activity, cells were exposed to the $\mathrm{Na}^{+}$channel blocker tetrodotoxin (TTx) for 24 hours, and the FM1-43 unloading kinetics were quantified at 7 DIV. TTx did not modify the number of functional boutons $(43.6 \pm 1.2 \%, P \geq 0.05)$ when compared with the control conditions (41.4 $\pm 9.2 \%)$, although there was a decrease in the proportion of nerve terminals displaying a strong dye loss profile $(30.4 \pm 6.6 \%$ compared with $63.9 \pm 7.4 \%$ under control conditions, $P \leq 0.05$ ). By contrast, TTx increased the proportion of synaptic terminals with weak 
A
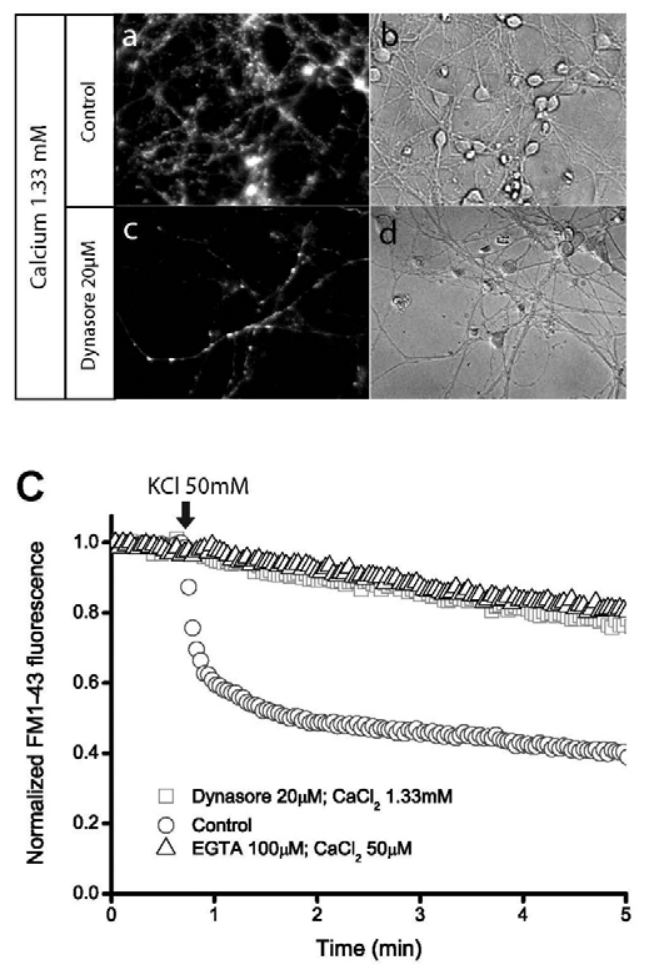

E

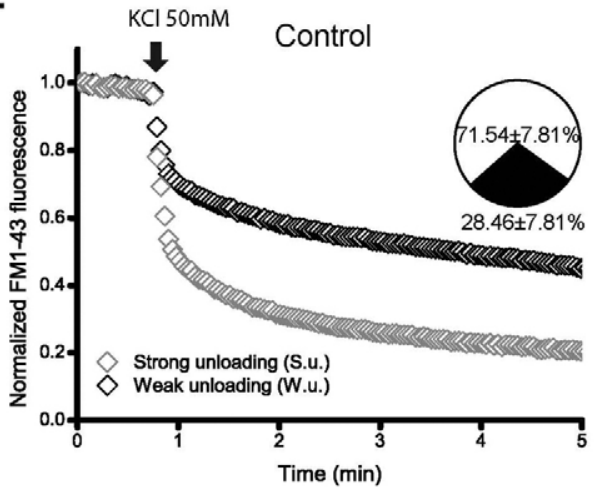

B

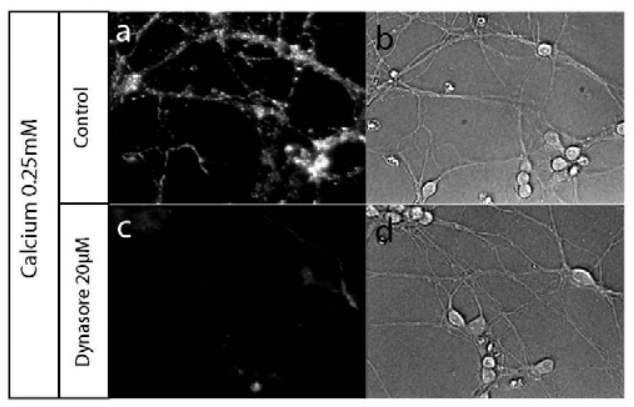

D

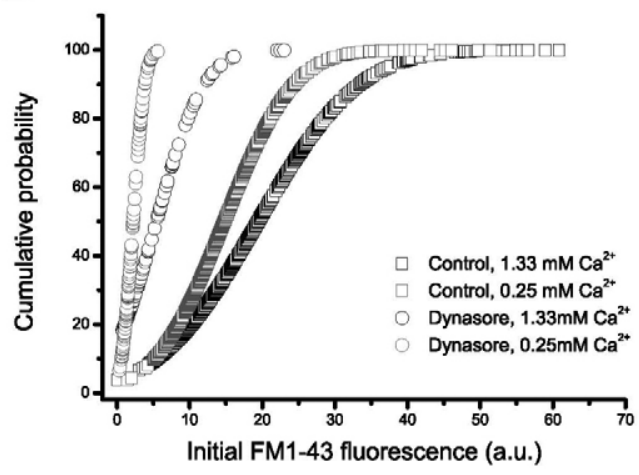

$\mathbf{F}$

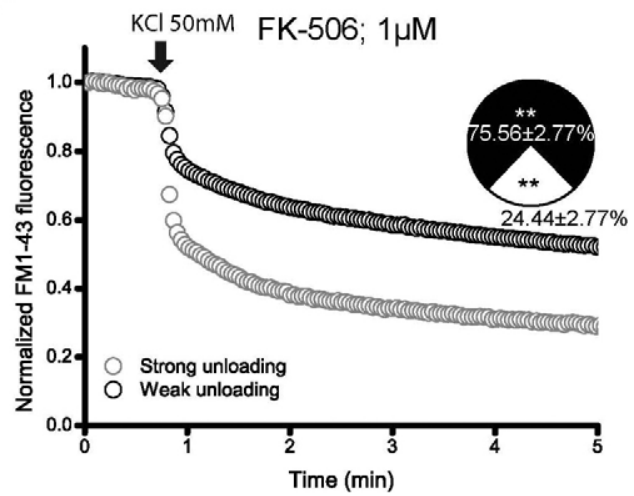

Fig. 5. The dynamin GTPase inhibitor dynasore completely prevents FM1-43 unloading, whereas the calcineurin inhibitor FK-506 dramatically reduces the proportion of synaptic boutons exhibiting strong FM1-43-unloading. FM1-43 images prior to the unloading of 7 DIV cerebellar granule cells labeled in the absence $(\mathbf{A}, \mathbf{B})$ or in the presence $(\mathbf{C}, \mathbf{D})$ of dynasore at normal $\left(1.3 \mathrm{~m} \mathrm{CaCl}_{2} ; \mathrm{A}\right)$ or low $\left(0.25 \mathrm{mM} \mathrm{CaCl}_{2} ; \mathrm{B}\right) \mathrm{Ca}^{2+}$ concentrations. Note that the puncta labeled at $1.3 \mathrm{mM} \mathrm{CaCl}_{2}$ are not detected in $0.25 \mathrm{mM} \mathrm{CaCl}_{2}$. (C) Average kinetics of FM1-43 loss in control cells maintained in medium containing $1.33 \mathrm{mM} \mathrm{Ca}{ }^{2+}$ [100 $\mu \mathrm{M}$ ethylene glycol tetraacetic acid (EGTA) with $50 \mu \mathrm{M} \mathrm{Ca}^{2+}$ ], and in cells treated with dynasore $(20 \mu \mathrm{M}, 30$ minutes) before and during the 5 minute loading step. (D) Cumulative probability of the initial FM1-43 fluorescence measured before unloading with $50 \mathrm{mM} \mathrm{KCl}$ in the presence or absence of dynasore (20 $\mu \mathrm{M}$, 30 minutes), both at normal $(1.33 \mathrm{mM})$ and low $(0.25 \mathrm{mM}) \mathrm{CaCl}_{2}$ concentrations. The mean initial fluorescence (a.u.) in control synaptic boutons was $19.4 \pm 0.49$ and $14.7 \pm 0.3\left(P \leq 0.01\right.$; ANOVA) at high $\mathrm{CaCl}_{2}$ concentrations and in the presence of dynasore, respectively, and it was $5.42 \pm 0.5$ and $2.22 \pm 0.11(P \leq 0.01$, ANOVA) at low $\mathrm{CaCl}_{2}$ concentrations. Average unloading kinetics of nerve terminals with strong and weak FM1-43-unloading profiles in 8 DIV control cells $(n=882$, six field; E), and in 8 DIV cells treated with the calcineurin inhibitor FK-506 $(1 \mu \mathrm{M}, 35$ minutes: $n=993$, six fields; F). The calcineurin inhibitor was added for 30 minutes before and during the loading step. The inserted pie chart shows the percentage of nerve terminals exhibiting strong and weak FM1-43-unloading kinetics. Data represent mean \pm s.e.m. n.s. $P \geq 0.05 ; * * P \leq 0.01$, when compared with the corresponding value under standard loading conditions ( $t$-test).

dye-unloading $(69.6 \pm 6.6 \%$ in the presence of TTx and $36.1 \pm 7.4 \%$ in the absence of TTx, $P \leq 0.05$, Fig. 7A). TTx did not affect the mean extent of dye unloading in nerve terminals exhibiting a weak dye loss $(38.8 \pm 1.8 \%$ in the control and $37.5 \pm 1.9$ in the presence of TTx, $P \geq 0.05)$ or a strong dye loss $(60.3 \pm 1.1 \%$ in the control and $56.3 \pm 1.6 \%$ in the presence of TTx, $P \geq 0.05$, Fig. 7B).
Thus, changes in synaptic vesicle recycling are largely dependent upon $\mathrm{Na}^{+}$-channel-driven synaptic activity.

In addition, we tested whether neuronal maturation involves an increase in the expression of synaptic proteins, such as dynamin, syntaxin, synaptojanin and synapsin. Syntaxin is a small integral plasma membrane protein that is abundantly expressed in 

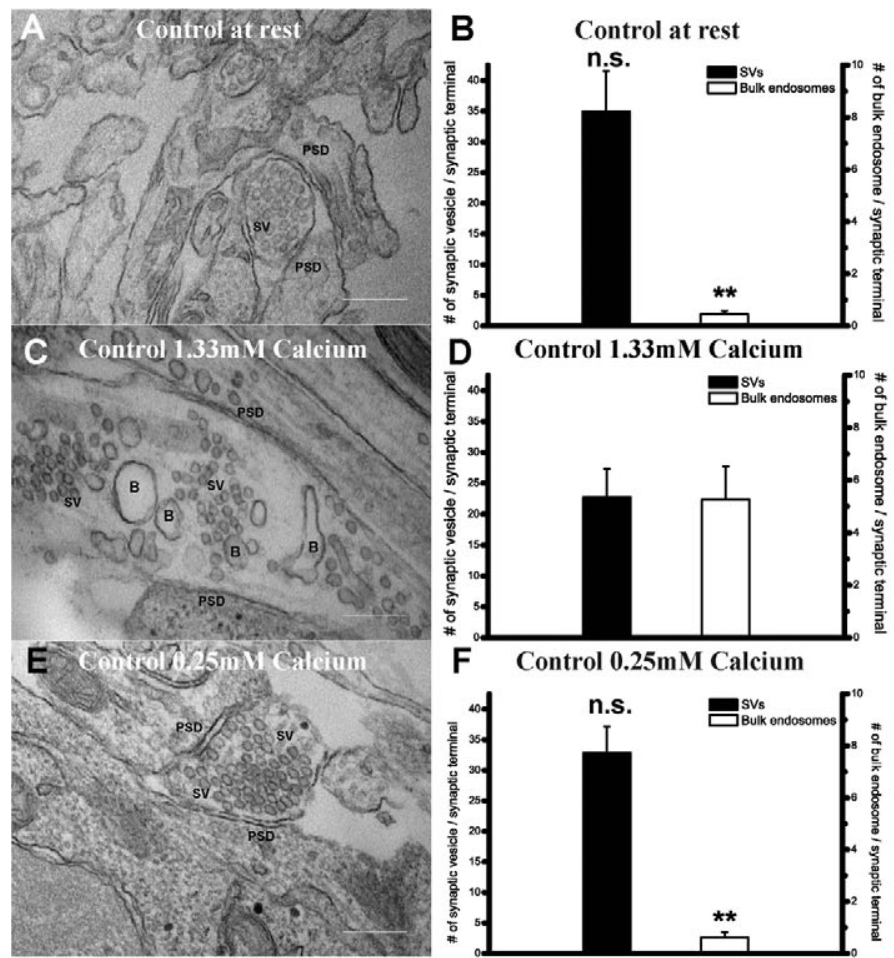
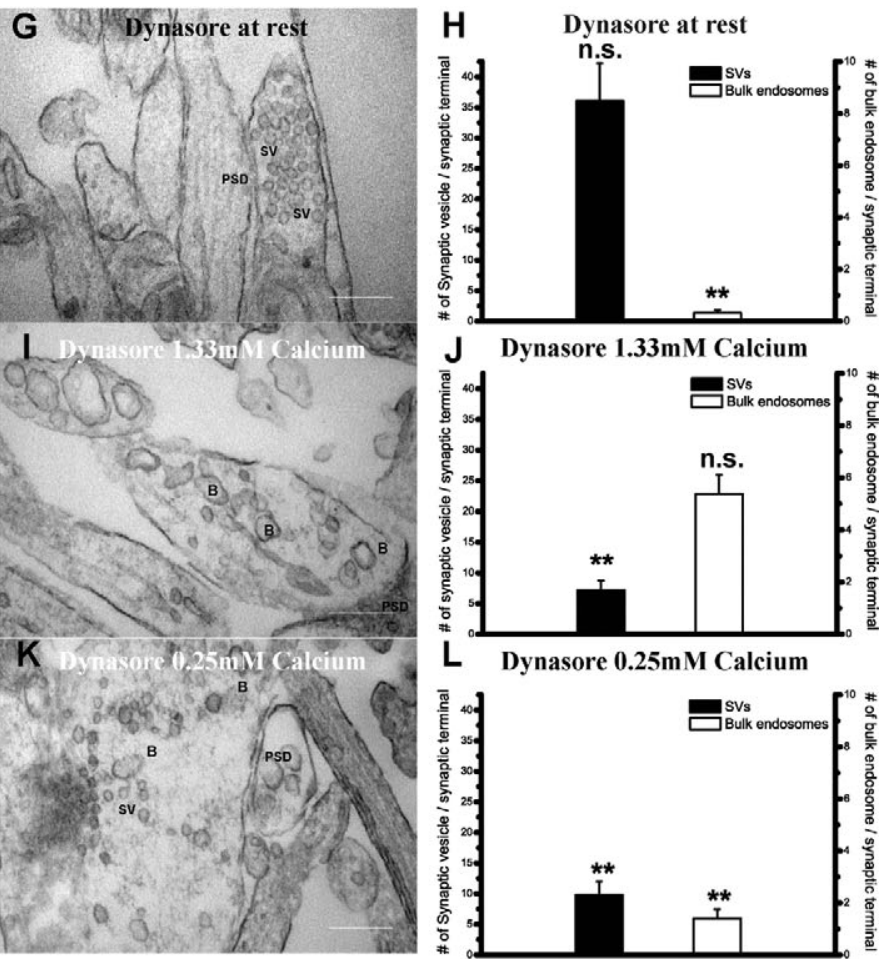

Fig. 6. The dynamin inhibitor dynasore largely reduces the number of small synaptic vesicles while promoting the formation of large endosomal vesicles. For electron microscopy, some cells were maintained under resting conditions ( $5 \mathrm{mM} \mathrm{KCl})$ whereas others were stimulated ( $50 \mathrm{mM} \mathrm{KCl} \mathrm{for} 2$ minutes) to mimic the loading step, and then washed and maintained for 10 minutes to permit vesicle recycling. Experiments were performed under different conditions: (1) Control under resting conditions $(5 \mathrm{mM} \mathrm{KCl} ; \mathbf{A}, \mathbf{B})$; (2) control stimulated with physiological $\mathrm{Ca}^{2+}$ concentrations $\left(50 \mathrm{mM} \mathrm{KCl,} 1.3 \mathrm{mM} \mathrm{Ca}{ }^{2+}\right.$; C,D); (3) control stimulated with low $\mathrm{Ca}^{2+}$ concentrations $\left(50 \mathrm{mM} \mathrm{KCl}, 0.25 \mathrm{mM} \mathrm{Ca}^{2+}\right.$; E,F); (4) dynasore treatment (20 $\mu \mathrm{M}, 30$ minutes) to inhibit dynamin under resting conditions ( $5 \mathrm{mM} \mathrm{KCl} ; \mathbf{G}, \mathbf{H})$; (5) dynasore treatment $\left(20 \mu \mathrm{M}, 30\right.$ minutes) with stimulation at physiological $\mathrm{Ca}^{2+}$ concentrations $\left(50 \mathrm{mM} \mathrm{KCl}, 1.3 \mathrm{mM} \mathrm{Ca}^{2+} ; \mathbf{I}, \mathbf{J}\right)$; (6) dynasore treatment $\left(20 \mu \mathrm{M}, 30\right.$ minutes) with stimulation at low $\mathrm{Ca}^{2+}$ concentrations $\left(50 \mathrm{mM} \mathrm{KCl}, 0.25 \mathrm{mM} \mathrm{Ca}{ }^{2+} ; \mathbf{K}, \mathbf{L}\right)$. The data represent the mean \pm s.e.m., and n.s. $P \geq 0.05 ; * * P \leq 0.01$ when compared with the control conditions stimulated at physiological $\mathrm{Ca}^{2+} \mathrm{concentrations}(t$-test).

neurons. Indeed, syntaxin 1 is an essential component of the exocytotic fusion machinary that interacts with several other proteins, including its partners in the fusion complex (Calakos et al., 1994). Synapsins are neuron-specific phosphoproteins, which are exclusively associated with small synaptic vesicles synapsin I interacts with vesicle membranes, actin and spectrin. Notably, the phosphorylation of synapsin I by CaM kinase II mobilizes synaptic vesicles from the reserve pool to synaptic sites (Benfenati et al., 1992). Dynamin is a GTPase that is required for clathrin-mediated endocytosis - the dephosphorylation of dynamin acts as a trigger for endocytosis (Marks et al., 2001). Synaptojanin is the main lipid phosphatase that is present in nerve terminals (Cremona et al., 1999), and synaptojanin knockout mice exhibit defects in synaptic vesicle endocytosis, suggesting a universal role for this enzyme in all forms of synaptic vesicle endocytosis (Mani et al., 2007).

Western blots of protein extracts from 3 DIV (100\%) and 7 DIV cerebellar granule cells were probed for the different synaptic proteins. In all cases, an increase in the expression of these proteins was found at 7 DIV: dynamin $(179.4 \pm 15.5 \%, n=3$, $P \leq 0.05)$; syntaxin $(189.7 \pm 24.3 \%, n=3, P \leq 0.05)$; synaptojanin $(265.5 \pm 24.5 \%, n=3, P \leq 0.05)$ and synapsin I $(306.7 \pm 12.9 \%$, $n=3, P \leq 0.05)$. No further increase in the expression of these synaptic proteins was detected at 14 DIV: dynamin (216.6 $\pm 20.5 \%, n=3, P \geq 0.05)$; syntaxin $(180.6 \pm 17.3 \%, n=3$, $P \geq 0.05)$; synaptojanin $(268.4 \pm 20.4 \%, \quad n=3, \quad P \geq 0.05)$ and synapsin I $(289.6 \pm 49.2 \%, \quad n=3, \quad P \geq 0.05, \quad$ supplementary material Fig. S2).

We also tested whether the different vesicle recycling kinetics exhibited by synaptic boutons with strong and weak unloading profiles were associated with changes in the expression of the synaptic proteins. Accordingly, synaptic vesicles were loaded with FM1-43, and dye unloading kinetics were measured upon exposure to $50 \mathrm{mM} \mathrm{K}^{+}$to identify synaptic boutons with strong or weak dye-loss profiles. Subsequently, 'post hoc' immunocytochemical experiments were performed to recognize synaptic proteins with antibodies against the following proteins: bassoon; munc13-1; calcineurin; the GluA3 subunit of AMPA receptors; dynamin, P-synapsin I; synapsin I and the vesicular glutamate transporter vGlut 1 . No differences in synapsin I expression were observed between the two groups of nerve terminals (Fig. 8A,E), although nerve terminals with strong dyeunloading displayed stronger P-synapsin-1 and calcineurin expression than those with weak dye loss (Fig. 8B,C,F,G). Moreover, the expression of GluA3 AMPA receptor subunits was stronger in post-synaptic membranes facing nerve terminals with weak dye loss than in post-synaptic membranes facing nerve terminals exhibiting strong unloading (Fig. 8D,H). Synaptic boutons that underwent strong unloading expressed bassoon and munc13-1 proteins more intensely than those with weak dye loss (supplementary material Fig. S3), whereas no difference was observed in the expression of dynamin and 

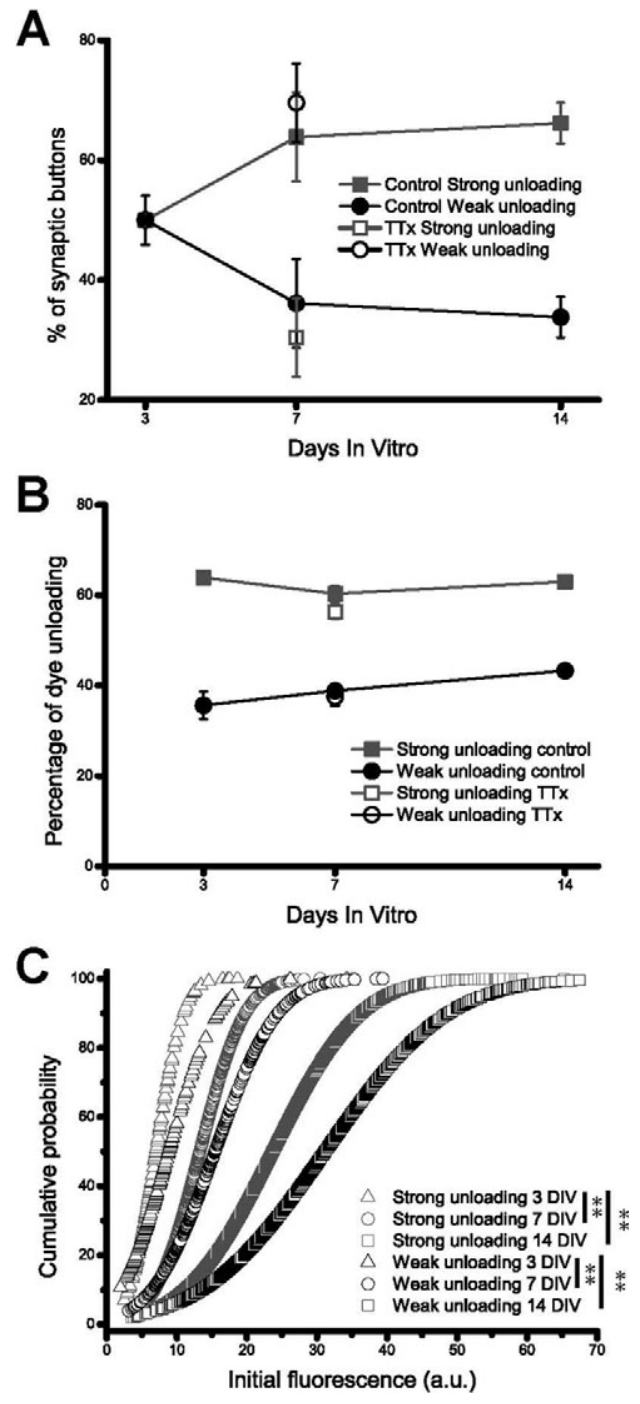

Fig. 7. Maturation of the cells in culture increases the proportion of nerve terminals exhibiting a strong unloading profile. (A) Percentage of nerve terminals with strong and weak FM1-43 dye loss as a function of time in culture. (B) Maturation of the cell culture does not alter the mean unloading of individual synaptic boutons. (C) The influence of cell culture maturation on the cumulative probability of initial FM1-43 fluorescence measured before unloading with $50 \mathrm{mM} \mathrm{KCl}$. Open symbols in A and B show the effect of tetrodotoxin $\left(1 \mu \mathrm{M}, 24\right.$ hours; n.s. $P \geq 0.05,{ }^{*} P \leq 0.05,{ }^{*} P \leq 0.01$ when compared with values at 3 DIV). Panels A and B were analyzed using a $t$-test. The tetrodotoxin data were compared with the corresponding data at 7 DIV in the absence of the $\mathrm{Na}^{+}$channel blocker (Panel C, Kolmogorov-Smirnov test).

vGlut1 between the two groups of nerve terminals (supplementary material Fig. S3).

\section{Discussion}

The FM1-43 dye that is taken up by synaptic vesicles after exocytosis then enters the endocytotic pathways that subsequently render vesicles competent for another round of exocytosis. Thus, the extent of FM1-43 unloading provides a measure of synaptic vesicle recycling at mammalian nerve terminals. The stimulation conditions that induce moderate exocytosis in cerebellar granule cells trigger synaptic vesicle recycling through a dynamin-dependent mechanism that is very efficient in generating releasable synaptic vesicles. However, conditions of massive exocytosis also activate a dynaminindependent form of endocytosis that involves the formation of non-releasable endosomes, which is characterized by nerve terminals that exhibit only a mild loss of FM1-43. The appearance of non-releasable endosomes is developmentally regulated, and their number diminishes as synapses mature. Indeed, the formation of non-releasable endosomes might play a role in maintaining the homeostasis of the membrane surface under conditions of massive exocytosis.

Synaptic vesicle recycling in cultured cerebellar granule cells is entirely dependent on dynamin activity, as demonstrated by the complete blockage of FM1-43 dye loss by dynasore, a selective inhibitor of dynamin-1 and -2 (Macia et al., 2006; Kirchhausen et al., 2008). This result is consistent with recent data showing that dynasore provokes a usage-dependent depression of evoked synaptic transmission at hippocampal GABAergic inhibitory synapses, indicating that evoked release originates from a pool of vesicles that rapidly recycle in a dynamin-dependent manner (Chung et al., 2010). The GTPase dynamin is required to 'pinch' synaptic vesicles from the plasma membrane during endocytosis (Praefcke and McMahon, 2004). Thus, the disruption of dynamin function arrests endocytosis at a late stage, before scission occurs in nerve terminals (Koenig and Ikeda, 1989). Furthermore, synaptic vesicle recycling in cultured cerebellar granule cells also appears to be sensitive to the calcineurin inhibitor FK-506. The protein phosphatase calcineurin initiates the dephosphorylation of a number of phosphoproteins [dynamin, amphyphysin, synaptojanin (Clayton and Cousin, 2009)]. Taken together, this dynamin- and calcineurin-dependent recycling of vesicles probably represents clathrin-mediated endocytosis, which efficiently generates synaptic vesicles that are competent for release.

In addition to clathrin-mediated endocytosis, bulk endocytosis also contributes to FM1-43 uptake in cultured cerebellar granule cells. The stimulation protocol that was used to initiate FM1-43 uptake $\left(50 \mathrm{mM} \mathrm{K} \mathrm{K}^{+}, 5\right.$ minutes) would be expected to induce large-scale exocytosis - a condition that initiates bulk endocytosis owing to the large number of synaptic vesicles that fuse with the plasma membrane (Harata et al., 2001; Andersson et al., 2008; Clayton et al., 2008). In addition, bulk endocytosis is typically characterized by large invaginations of the plasma membrane (Miller and Heuser, 1984) followed by fission to form endosome-like compartments - these structures were observed in our preparation after control stimulation. However, bulk endocytosis appears to contribute little to synaptic vesicle recycling under our experimental conditions, given the lack of endosome-like structures associated with the synaptic vesicle recycling, in which synaptic nerve terminals with strong unloading profiles prevail. Furthermore, in the presence of the dynamin inhibitor dynasore, which completely blocks dye unloading, there is no change in the number of endosome-like structures, despite the dramatic reduction in the number of synaptic vesicles. The capacity of cerebellar granule cell boutons to render releasable synaptic vesicles is therefore largely dynamin dependent, although some FM1-43 uptake occurs in a dynamin-independent manner. This dynamin-independent FM143 uptake is mediated by endosome-like structures that are formed during large-scale exocytosis and that fail to recycle into release-competent synaptic vesicles, at least within the timeframe of our experiments, thereby contributing to those nerve terminals exhibiting weak dye-unloading profiles. These 

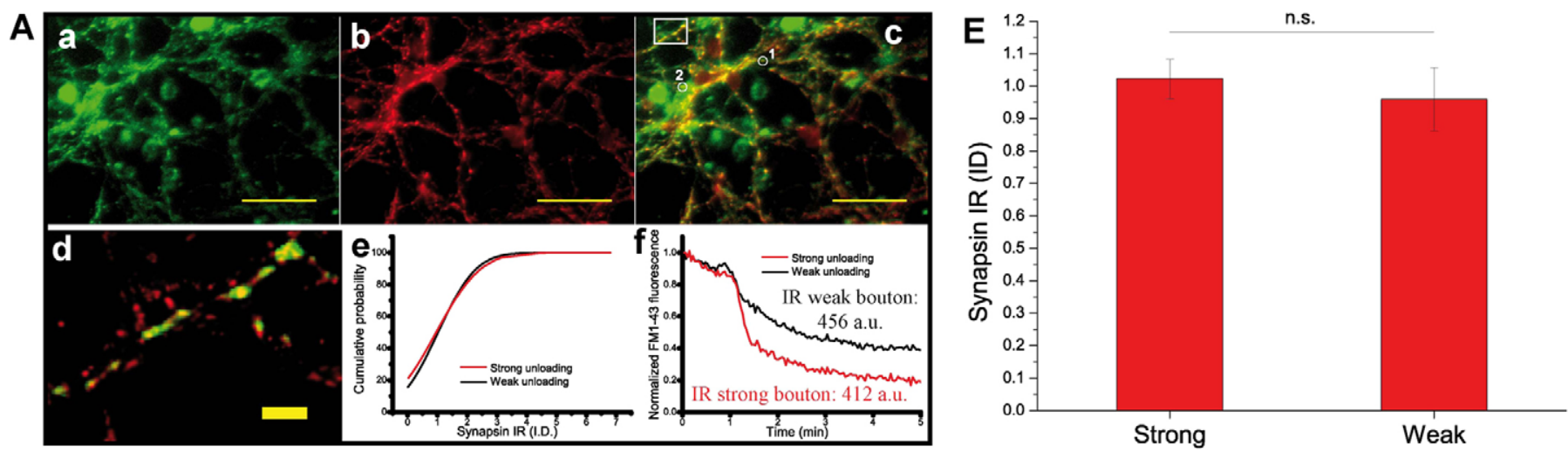

B

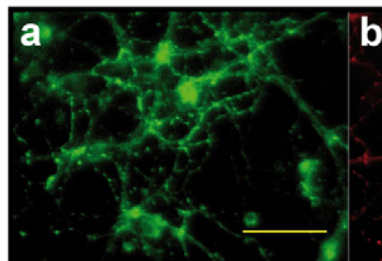

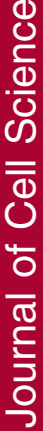

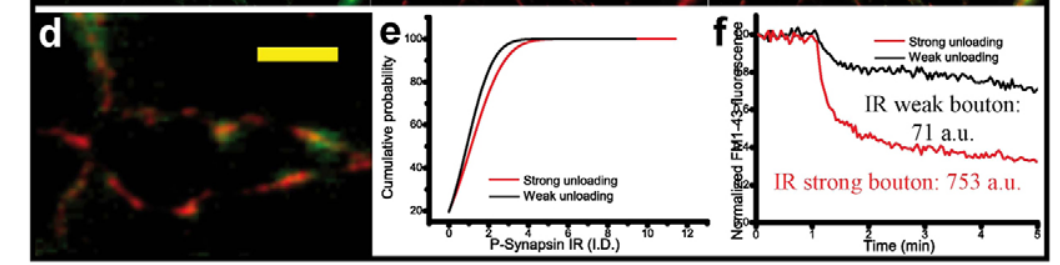

$\mathrm{c}$
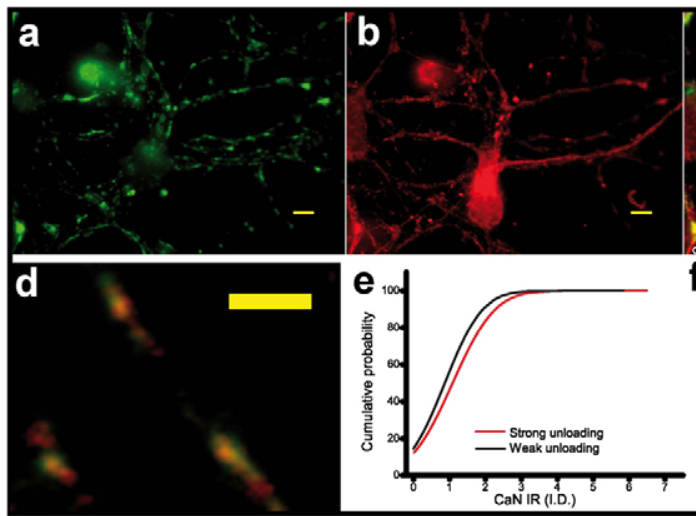

b
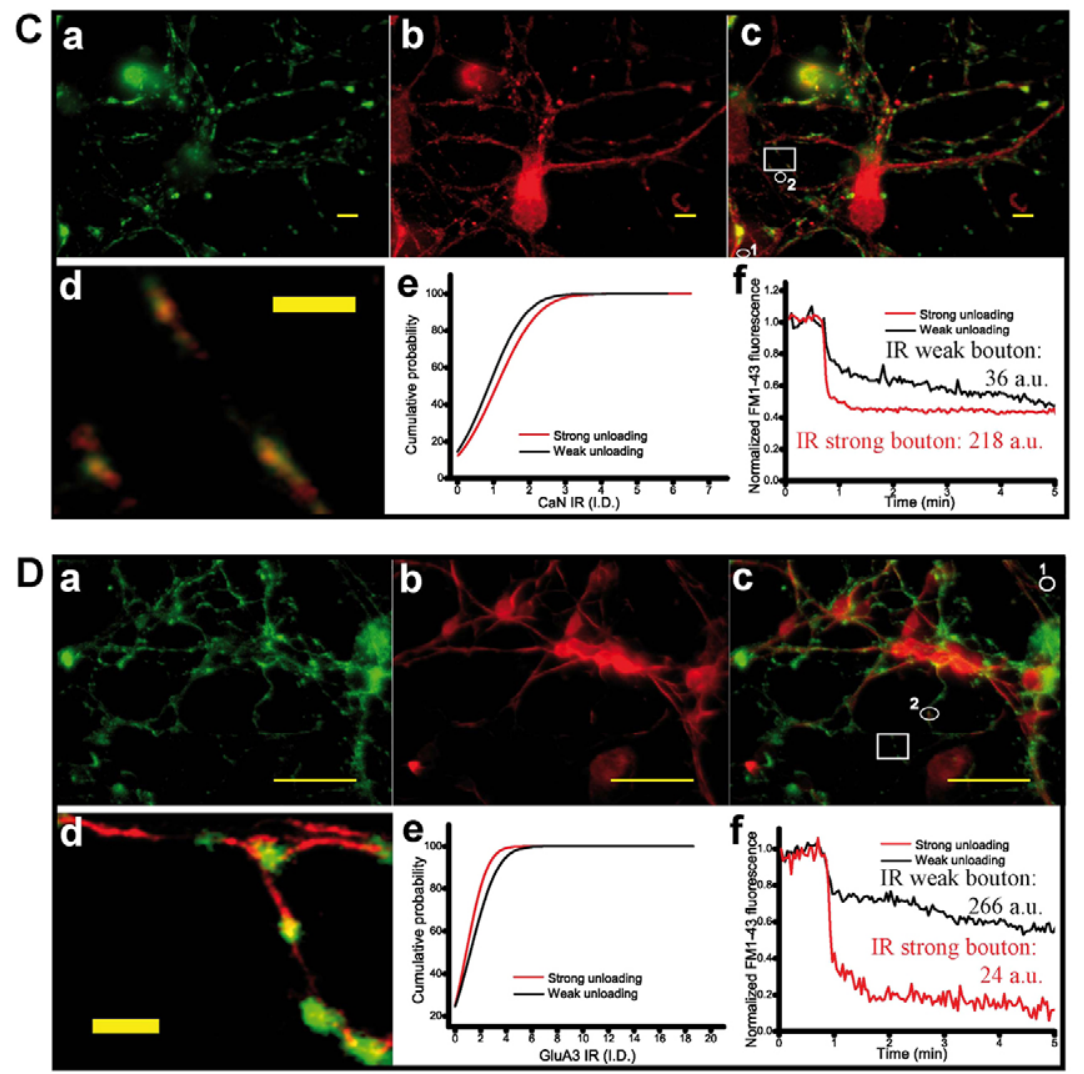

b
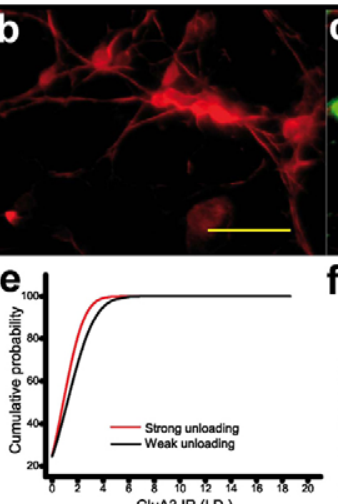
GIUA3 IR (I.D.)
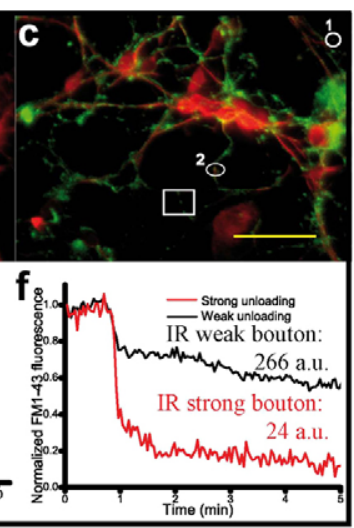

$F^{1.2}$
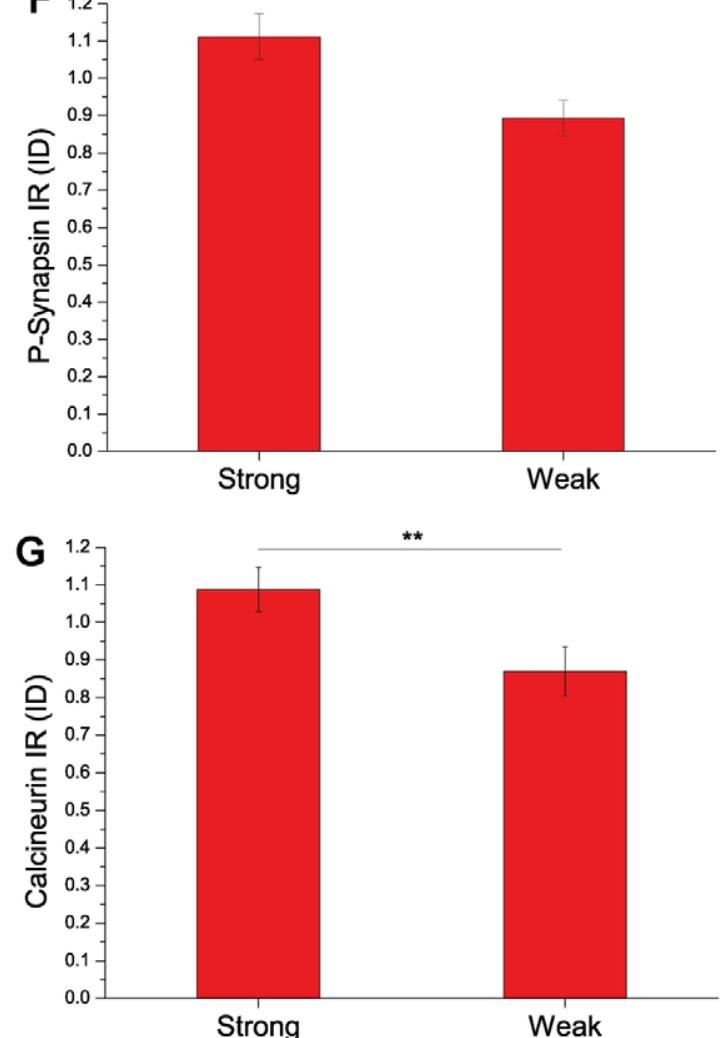

H

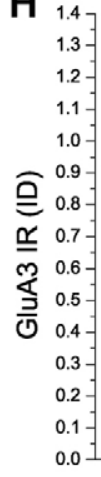

Fig. 8. See next page for legend. 
non-releasable endosomes have been observed in chromaffin cells, in which the endocytotic recycling response can be discriminated by the ability of the cells to generate releasable vesicles. Thus, mild stimulation with acetylcholine is followed by the total recovery of releasable vesicles, whereas a stronger stimulus with $50 \mathrm{mM} \mathrm{K}^{+}$that provokes intense exocytosis induces endocytosis that retrieves the entire fused membrane, although only a fraction of the endocyted membrane renders vesicles that can be released by a second stimulus (Perez Bay et al., 2007).

In primary neuronal cultures, activity-dependent bulk endocytosis has a high capacity for retrieving synaptic vesicles, which is immediately triggered during elevated neuronal activity and swiftly terminated when the stimulus is removed (Clayton and Cousin, 2009). In addition, activity-dependent bulk endocytosis produces synaptic vesicles that selectively repopulate the reserve synaptic vesicle pool (Richards et al., 2000). This form of activity-dependent bulk endocytosis is dynamin dependent [dynasore inhibits the generation both of synaptic vesicles and of bulk endosomes (Clayton et al., 2009)] and is dependent on both $\mathrm{Ca}^{2+}$ and calmodulin (Wu et al., 2009), which is consistent with the role of the protein phosphatase calcineurin as a trigger of this form of endocytosis (Cousin and Robinson, 2001; Lee et al., 2005). Other forms of bulk endocytosis are also activity dependent and are rapidly triggered, even though they persist for minutes after the stimulation terminates (Koenig and Ikeda, 1989; Koenig and Ikeda, 1996; Richards et al., 2000). This slow mode of bulk endocytosis was initially described in non-mammalian preparations, but it might also occur in mammalian neurons.

It is possible that the dynamin-independent uptake of FM1-43 that leads to the formation of non-releasable endosomes is not a vesicle-recycling mechanism but, rather, it resembles the plasma membrane endocytotic mechanism that occurs during developmental growth cone remodeling (Fournier et al., 2000; Jurney et al., 2002). Some features of this plasma membrane endocytosis are similar to the dynamin-independent uptake of FM1-43 that is observed in cerebellar granule cells, particularly since: (1) endocytic vesicles with vacuolar organization are visible after their exposure to large fluid-phase markers, which have restricted access to small vesicles; (2) plasma membrane bulk endocytosis does not colocalize with the synaptic vesicle marker VAMP-2 and it functions independently of clathrin and (3) bulk plasma membrane retrieval that is associated with growth cones is progressively downregulated during neuronal differentiation, although it coexists with synaptic vesicle

Fig. 8. Synaptic boutons with strong FM1-43-unloading profiles contain more P-synapsin and calcineurin and less GluA3 AMPA receptor subunit in postsynaptic membranes than those with weak unloading profiles.

(A) FM1-43 image, (B) immunofluorescence image and merged FM1-43 and immunofluorescence images at (C) low magnifications and (D) high magnifications. (E) Cumulative immunofluorescence of synapsin (A), Psynapsin (B), GluA3 (C) and calcineurin (D) in nerve terminals with strong and weak FM1-43-unloading profiles. (F) An example of nerve terminals with strong and weak unloading kinetics (shown as 1 and 2 in panel c,

respectively). Differences in protein immunoreactivity (IR) expressed as the normalized integrated density (ID) of the two synaptic bouton populations for synapsin (E), P-synapsin (F), calcineurin (G) and GluA3 (H). Integrated densities were normalized to the mean value of each experiment. The results shown in E, F, G and $\mathrm{H}$ represent the mean \pm s.e.m. of at least three experiments, n.s. $P \geq 0.05$ and ${ }^{* *} P \leq 0.01$ ( $t$-test), when comparing nerve terminals with strong versus weak unloading profiles. recycling at the early developmental stages. This membrane retrieval pathway might account for the efficient remodeling of the growth cone membrane during the early stages of neuronal development. Such a process might serve as a mechanism for maintaining membrane homeostasis, preventing changes in the size of the nerve terminal, although the molecular mechanism of this dynamin-independent recycling remains to be established.

Although the capacity to recycle synaptic vesicles augments during development, fewer nonreleasable endosomes are formed through bulk-endocytosis, resulting in nerve terminals with a greater capacity to recycle FM1-43. Our post hoc immunocytochemistry studies indicate that synaptic boutons that are more efficient at recycling synaptic vesicles express higher levels of synaptic proteins, such as calcineurin $\left(\mathrm{a} \mathrm{Ca}^{2+}\right.$ calmodulin-dependent protein phosphatase), bassoon, munc13-1 and P-synapsin I. The increase in the expression of calcineurin in nerve terminals with more efficient synaptic vesicle recycling is consistent with the capacity for this enzyme to dephosphorylate several substrates that are essential for synaptic vesicle recycling - for example, the dephosphins (Cousin and Robinson, 2001; Lee et al., 2005). The vesicle pool is organized during synaptic development, and, once the readily releasable pool of synaptic vesicles is formed, the number of vesicles at the synapse increases to build up the reserve pool (Mozhayeva et al., 2002). We demonstrate that synaptic terminal maturation is associated with the increased expression of P-synapsin I. The phosphorylation of synapsin I by CaM kinase II results in the mobilization of synaptic vesicles from the reserve pool to synaptic sites - this mobilization is associated with an increased capacity to maintain neurotransmitter release during prolonged periods of activity (Benfenati et al., 1992). Munc13-1 belongs to a family of active-zone proteins that are essential for the priming of synaptic vesicles to make them fusion competent (Betz et al., 1998). The increased expression of munc13-1 in nerve terminals that display more efficient synaptic vesicle recycling demonstrates parallel changes in the exocytotic and endocytotic stages of the synaptic vesicle cycle in nerve terminals.

\section{Materials and Methods}

\section{Primary culture of cerebellar neurons}

All animal care procedures were performed in accordance with our institutes' ethical guidelines for animal experiments and the regulations established in the European Council Directive (86/609/EEC). Primary dissociated cerebellar cultures were derived from the cerebellum of 7-day-old (P7) male or female Wistar albino rat pups, as described previously (Jurado et al., 2003). Isolated cerebellar cells were diluted in Neurobasal A supplemented with B27 (Invitrogen), $15 \mathrm{mM} \mathrm{KCl}$, $0.5 \mathrm{mM}$ glutamine and a stabilized antibiotic-antimycotic solution (Sigma). The cells were seeded onto poly-L-lysine-coated coverslips at a density of $1-3 \times 10^{5}$ cells per coverslip, or in 96- or six-well tissue-culture plates at $2 \times 10^{5}$ or $3.5 \times 10^{6}$ cells per well, respectively. The cultures were maintained in a humidified atmosphere of $5 \% \mathrm{CO}_{2}$ at $37^{\circ} \mathrm{C}$. After 24 hours in culture, $10 \mu \mathrm{M}$ cytosine- $\beta$-Darabinofuranoside (Sigma) was added to restrict glial cell growth. The cultures were routinely used for experiments between 3 and 14 DIV.

\section{Synaptic bouton activity (FM1-43)}

We analyzed endocytosis-exocytosis as a measure of synaptic bouton function. This strategy is based on the uptake and unloading of the styryl dye FM1-43 (Molecular Probes, Invitrogen) by granule cells that are plated on coverslips at a density of $3 \times 10^{5}$ cells per coverslip. Cells were incubated for 10 minutes in a $\mathrm{Ca}^{2+}$-free and low-K $\mathrm{K}^{+}$buffer $\left[140 \mathrm{mM} \mathrm{NaCl}, 5 \mathrm{mM} \mathrm{KCl}, 5 \mathrm{mM} \mathrm{NaHCO} 3,1.2 \mathrm{mM} \mathrm{NaH}_{2} \mathrm{PO}_{4}\right.$, $1 \mathrm{mM} \mathrm{MgCl}, 10 \mathrm{mM}$ glucose, $10 \mathrm{mM}$ HEPES (pH 7.4)] and were then incubated for 5 minutes with $10 \mu \mathrm{M}$ FM1-43 dye in high- $\mathrm{K}^{+}$buffer $[10 \mathrm{mM}$ HEPES (pH 7.4),

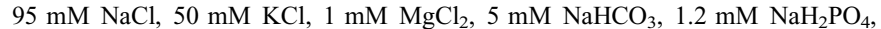
$1.33 \mathrm{mM} \mathrm{CaCl}_{2}, 10 \mathrm{mM}$ glucose], followed by a 10 minute wash by perfusion with $\mathrm{a} \mathrm{Ca}^{2+}$-free low-K $\mathrm{K}^{+}$buffer to remove the surface-bound dye. Baseline measurements were then acquired over 30 seconds by perfusing with a low- $\mathrm{K}^{+}$medium and then stimulating the cells for 5 minutes in a high- $\mathrm{K}^{+}$medium, leading to dye unloading 
(Fig. 1A). To analyze the $\mathrm{Ca}^{2+}$ dependence of FM1-43 uptake, the $\mathrm{Ca}^{2+}$ concentration during incubation in the presence of the dye was changed to 0.5 or $0.25 \mathrm{mM}$. Dye concentrations were also modified during the loading step (5 $\mu \mathrm{M}$ and $3 \mu \mathrm{M})$ to determine the effect on synaptic bouton labeling. Images were captured using a Nikon microscope equipped with a Nikon $\times 401.3$ numerical aperture oilimmersion objective and a CCD camera (Hamamatsu 4880) at a rate of one frame every 2 seconds. Excitation was provided by a $479 \mathrm{~nm}$ monochromator, and emitted light was collected using a fluorescein isothiocyanate (FITC) filter.

\section{Analysis of FM1-43 experiments}

Different fields were selected at random and individual synaptic boutons were analyzed. Regions of interest (ROIs) were identified using Igor Pro software, indicating the presence of synaptic boutons, according to the automated method described previously (Bergsman et al., 2006), with a minimum quality criterion for analysis of 0.1 . This criterion is established according to three measurements: the coefficient of variation (CV) of the baseline, the slope of the baseline and the final extent of dye unloading. Dye unloading kinetics were determined after normalization by subtracting the mean background fluorescence and then dividing by the initial fluorescence value of each ROI (F/F0). When the extent of dye release was determined, we subtracted the mean background fluorescence of several cell-free regions in order to observe differences in the extent of dye release.

The mask obtained from the Igor Pro software after running the routine was used to reprocess manually the experimental data to ensure that the boutons analyzed reached the minimal quality and to sort them into two subpopulations based on the extent of dye release (Fig. 1). Given that the background subtraction of the routine is based on an iterative strategy, some of the boutons matching the firs classification criteria can be rendered ineffective after background subtraction. Thus, we reprocessed the data in accordance with the same three criteria described above: (1) proper FM1-43 unloading in response to stimulation (>10\%); (2) a coefficient of variation of the base line lower than $10 \%$; and (3) stability of the baseline slope. The responses were heterogeneous in terms of dye release (Fig. 1F), but, despite this heterogeneity, two subpopulations of synaptic boutons could be distinguished (Fig. 1G). The frequency histogram (Fig. 1G) fits with two Gaussian curves that have an intersect value of $42.1 \pm 2.6 \%$. Based on these results, we characterized the nerve terminals that released less than $40 \%$ of the dye as belonging to the weak unloading group, and the nerve terminals that released over $40 \%$ as belonging to the strong releasing group. Where indicated, the bouton density was calculated by dividing the overall number of functional synaptic boutons by the entire neurite length in each experiment. The total neurite length was measured by using the NeuronJ plugin of ImageJ (Meijering et al., 2004).

\section{Electron microscopy}

To visualize synaptic vesicle turnover within presynaptic terminals, cultured cerebellar granule cells were stimulated for 5 minutes with HBM medium containing $50 \mathrm{mM} \mathrm{K}^{+}$, and they were then maintained for 10 minutes in $5 \mathrm{mM} \mathrm{K}^{+}$ HBM, emulating our routine protocol. After stimulation, the cells were washed twice with buffer and fixed for 2 hours at $4{ }^{\circ} \mathrm{C}$ with $4 \%$ paraformaldehyde and $2.5 \%$ glutaraldehyde in Millonig's sodium phosphate buffer $(0.1 \mathrm{M}, \mathrm{pH}$ 7.3). The cells were then washed twice and stored overnight at $4^{\circ} \mathrm{C}$ in Millonig's buffer, and they were then post-fixed in $1 \% \mathrm{OsO}_{4}$ for 1 hour at room temperature and dehydrated in ethanol. To detach the cell layer from the plate, the cells were treated with propylene oxide before the entire monolayer was collected and embedded in SPURRembedded kit (TAAB, Berkshire, UK) for 24 hours. Ultrathin sections (70 $\mathrm{nm}$ ) were routinely stained with uranyl acetate and lead citrate, and images were captured using a JEOL 1200 EX II transmission electron microscope Measurements were obtained with the aid of ImageJ software.

\section{Western blotting}

Protein extracts were separated on $8-10 \%$ sodium dodecyl sulphatepolyacrylamide gels and transferred electrophoretically onto nitrocellulose membranes (Hybond, Amersham Biosciences), as described previously (Jurado et al., 2004). The membranes were probed with primary antibodies raised agains dynamin (cat. no. 115002, Synaptic Systems), synapsin-1 (cat. no. 106001, Synaptic Systems), synaptojanin-1 (cat. no. 145003, Synaptic Systems), syntaxin (cat. no. 110001, Synaptic Systems), $\beta$-tubulin (cat. no. T0198, Sigma) or GAPDH (cat. no. AM4300, Applied Biosystems). After several washes, the membranes were incubated with the corresponding IRD-labeled secondary antiserum; goa polyclonal anti-mouse IRDye 680 (cat. no. 926-32220), goat polyclonal antimouse IRDye 800 (cat. no. 926-32210) or goat polyclonal anti-rabbit IRDye 800 (cat. no. 926-32211) (LI-COR Biosciences). The blots were scanned using an Odyssey Infrared imaging system, and the immunoreactive proteins were compared by densitometry and quantified using Odyssey 2.0 software. The GAPDH signal was used as a loading control.

\section{Post hoc immunocytochemistry}

To identify the field analyzed in the functional (FM1-43) experiments, the chambers subjected to post hoc immunohistochemistry were marked to ensure their position.
After FM1-43 unloading, the cells were fixed with 4\% paraformaldehyde in PBS for 15 minutes at room temperature, rinsed twice briefly with PBS and were then permeabilized with $0.2 \%$ Triton X-100 for 6 minutes. The cells were then blocked with PBS containing $0.05 \%$ Triton X-100 and $10 \%$ normal donkey serum for 1 hour at $37^{\circ} \mathrm{C}$ and then incubated for 24 hours at $4{ }^{\circ} \mathrm{C}$ with primary antibodies diluted in PBS containing $5 \%$ normal donkey serum and $0.05 \%$ Triton X-100. The following antibodies were used at the concentrations indicated: guinea pig polyclonal antiBassoon, 1:500 (cat. no. 141004, Synaptic Systems); rabbit polyclonal anti-phosphosynapsin I, 1:400 (cat. no. 07-567, Millipore); mouse monoclonal anti-Munc 13-1, 1:1000 (cat. no. 126111, Synaptic Systems); mouse monoclonal anti-calcineurin (PP2B), 1:50 (cat. no. 610259, BD Transduction Laboratories); mouse monoclonal anti-GluR3, 1:200 (cat. no. MAB5416, Millipore); rabbit polyclonal anti-dynamin 1:400 (cat. no. 115002, Synaptic Systems); mouse monoclonal anti-synapsin 1, 1:250 (cat. no. 106001, Synaptic Systems); rabbit polyclonal anti-vesicular glutamate transporter 1 (V-GLUT1), 1:200 (cat. no. 135302, Synaptic Systems). After washing, the coverslips were incubated with the following fluorescent secondary antibodies diluted in PBS containing 5\% normal donkey serum and $0.05 \%$ Triton X-100: Alexa Fluor 488 goat anti-mouse, 1:200 (cat. no. A11001, Molecular Probes, Invitrogen); Alexa Fluor 488 goat anti-rabbit, 1:200 (cat. no. A11008, Molecular Probes, Invitrogen); Alexa Fluor 546 goat anti-guinea pig 1:200 (cat. no. A11074, Molecular probes, Invitrogen) or Alexa Fluor 594 goat anti-mouse, 1:200 (cat. no. A11005, Molecular Probes, Invitrogen). Following several washes in PBS, the coverslips were mounted with prolong antifade (Invitrogen) and the cells were visualized on a Nikon Diaphot microscope equipped with $\times 401.3 \mathrm{NA}$ or $\times 1001.3 \mathrm{NA}$ oil-immersion fluor objectives, a mercury lamp light source and fluorescein or rhodamine Nikon filter sets. Images were obtained using a slow-scan CCD camera (cat. no. C4880, Hamamatsu) operating at 8-bit digitization (256 levels), and the camera output was stored on a computerized imaging system (Kinetic Imaging). The exact field analyzed in the experiment was located by capturing phase-contrast images for reference. To confirm the specificity of the antibodies used, the cells were incubated with the secondary antibodies alone, in the absence of the primary antibodies.

For quantitative analysis, all the images were acquired at identical brightness and contrast settings. Background subtraction was carried out using the ImageJ plugin, based on the rolling ball radius algorithm (Sternberg, 1983) and applying a radius of three pixels for all the images. Spurious ROIs were removed manually. The mask obtained using the Igor Pro software from the FM1-43 experiment was superimposed onto the immunocytochemistry images, using the 'Align RGB planes' tool to align the image correctly. After alignment, some of the ROIs did not exactly match with immunoreactive puncta, particularly at the edges of the image, and they were therefore excluded from the analysis. To quantify the staining adequately and to correlate the intensity of staining of individual synaptic termini with the amount of protein (even though these two parameters were not linearly related), staining intensities were measured as grey-scale values (ranging from zero to 255) by using the ImageJ software. Similarly, the integrated density value was calculated as the sum of the grey values for each of the different pixels defined within a given ROI. To sort the boutons, we grouped the immunoreactivity values that were obtained according to the fluorescence extinction kinetics of the boutons, which allowed us to correlate the amounts of protein with functional features of the boutons.

\section{Statistical analysis}

The data were analyzed using the Statgraphic, OriginPro 7.5 or SigmaPlot 10 statistical software. The specific test applied in each case is indicated in the figure legend or the text. Data are shown as the mean \pm s.e.m.: * indicates $P<0.05$, ** indicates $P<0.01$ and $* * *$ indicates $P<0.001$. ImageJ, Lucida Analyse 4 (Kinetic Imaging) and Soft Imaging Viewer (Soft Imaging System) software were used for image processing. Differences were considered statistically significant at $P<0.05$, with a confidence limit of $95 \%$.

\section{Acknowledgements}

We thank Mark Sefton for editorial assistance. We also thank Agustin Fernandez and Marisa Garcia from the electron microscopy facility, Universidad Complutense Madrid (UCM), for their technical support.

\section{Funding}

This work was financed by grants from the Spanish 'Ministerio de Educación y Ciencia' [grant numbers BFU2006-01012 and BFU2009-07092 to M.T., and BFU2007-64154 and BFU2010-16947 to J.S.-P.]; the 'Instituto de Salud Carlos III' [grant number RD06/ 0026 to J.S.-P. and M.T.]; the 'Comunidad de Madrid' [grant number S-BIO-0170/2006 to J.S.-P. and M.T.]; and the UCM-CAM [grant number CCG07-UCM/SAL-2150 to J.S.-P. and M.T.]

Supplementary material available online at http://jcs.biologists.org/lookup/suppl/doi:10.1242/jcs.090878/-/DC1 


\section{References}

Andersson, F., Jacobsson, J., Low, P., Shupliakov, O. and Brodin, L. (2008). Perturbation of syndapin/PACSIN impairs synaptic vesicle recycling evoked by intense stimulation. J. Neurosci. 28, 3925-3933.

Aravanis, A. M., Pyle, J. L. and Tsien, R. W. (2003). Single synaptic vesicles fusing transiently and successively without loss of identity. Nature 423, 643-647.

Balaji, J. and Ryan, T. A. (2007). Single-vesicle imaging reveals that synaptic vesicle exocytosis and endocytosis are coupled by a single stochastic mode. Proc. Natl. Acad. Sci. USA 104, 20576-20581.

Benfenati, F., Valtorta, F., Rubenstein, J. L., Gorelick, F. S., Greengard, P. and Czernik, A. J. (1992). Synaptic vesicle-associated $\mathrm{Ca}^{2+} /$ calmodulin-dependent protein kinase II is a binding protein for synapsin I. Nature 359, 417-420.

Bergsman, J. B., Krueger, S. R. and Fitzsimonds, R. M. (2006). Automated criteriabased selection and analysis of fluorescent synaptic puncta. J. Neurosci. Meth. 152, 32-39.

Betz, A., Ashery, U., Rickmann, M., Augustin, U., Neher, E., Südhof, T. C., Rettig, J. and Brose, N. (1998). Munc-13-1 is a presynaptic phorbol ester receptor that enhances neurotransmitter release. Neuron 21, 123-136.

Ceccarelli, B., Hurlbult, W. P. and Mauro, A. (1973). Turnover of transmitter and synaptic vesicles at the frog neuromuscular junction. J. Cell Biol. 57, 499-524.

Calakos, N., Bennet, M. K., Peterson, K. E. and Scheller, R. H. (1994). Proteinprotein interactions contributing to the specificity of intracellular vesicular trafficking. Science 263, 1146-1149.

Chung, C., Barylko, B., Leitz, J., Liu, X. and Kavalali, E. T. (2010). Acute dynamin inhibition dissects synaptic vesicle recycling pathways that drive spontaneous and evoked neurotransmission. J. Neurosci. 30, 1363-1376.

Clayton, E. L. and Cousin, M. A. (2009). The molecular physiology of activitydependent bulk endocytosis of synaptic vesicles. J. Neurochem. 111, 901-914.

Clayton, E. L., Evans, G. J. and Cousin, M. A. (2008). Bulk synaptic vesicle endocytosis is rapidly triggered during strong stimulation. J. Neurosci. 28, 6627-6632.

Clayton, E. L., Anggono, V., Smillie, K. J., Chau, N., Robinson, P. J. and Cousin, M. A. (2009). The phospho-dependent dynamin-syndapin interaction triggers activity-dependent bulk endocytosis of synaptic vesicles. J. Neurosci. 29, 7706-7717.

Cousin, M. A. and Robinson, P. J. (2001). The dephosphins: dephosphorylation by calcineurin triggers synaptic vesicle endocytosis. Trends Neurosci. 24, 659-665.

Cremona, O., Di Paolo, G., Wenk, M. R., Lüthi, A., Kim, W. T., Takei, K., Daniell, L., Nemoto, Y., Shears, S. B., Flavell, R. A. et al. (1999). Essential role of phosphoinositide metabolism in synaptic vesicle recycling. Cell 99, 179-188.

Fournier, A. E., Nakamura, F., Kawamoto, S., Goshima, Y., Kalb, R. G. and Strittmatter, S. M. (2000). Semaphorin3A enhances endocytosis at sites of receptorF-actin colocalization during growth cone collapse. J. Cell Biol. 149, 411-422.

Gandhi, S. P. and Stevens, C. F. (2003). Three modes of synaptic vesicle recycling revealed by single-vesicle imaging. Nature 423, 607-613.

Granseth, B., Odermatt, B., Royle, S. J. and Lagnado, L. (2006). Clathrin-mediated endocytosis is the dominant mechanism of vesicle retrieval at hippocampal synapses. Neuron 51, 773-786.

Harata, N., Ryan, T. A., Smith, S. J., Buchanan, J. and Tsien, R. W. (2001). Visualizing recycling synaptic vesicles in hippocampal neurons by FM1-43 photoconversion. Proc. Natl. Acad. Sci. USA 98, 12748-12753.

Heuser, J. E. (1989). Review of electron microscopic evidence favouring vesicle exocytosis vesicle exocytosis as the structural bases for quantal release during synaptic transmission. Q. J. Exp. Physiol. 74, 1051-1069.

Heuser, J. E. and Reese, T. S. (1973). Evidence for recycling of synaptic vesicle membrane during transmitter release at the frog neuromuscular junction. J. Cell Biol. 57, 315-344.

Holt, M., Cooke, A., Wu, M. M. and Lagnado, L. (2003). Bulk membrane retrieval in the synaptic terminal of retinal bipolar cells. J. Neurosci. 23, 1329-1339.

Jurado, S., Sánchez-Prieto, J. and Torres, M. (2003). Differential expression of NOsensitive guanylyl cyclase subunits during the development of cerebellar granule cells: regulation via N-methyl-D-aspartate receptors. J. Cell Sci. 116, 3165-3175.
Jurado, S., Sánchez-Prieto, J. and Torres, M. (2004). Elements of the nitric oxide/ cGMP pathway expressed in cerebellar granule cells: biochemical and functional characterization. Neurochem. Int. 45, 833-843.

Jurney, W. M., Gallo, G., Letourneau, P. C. and McLoon, S. C. (2002). Rac1 mediated endocytosis during ephrin-A2- and semaphoring $3 \mathrm{~A}$-induced growth cone collapse. J. Neurosci. 2, 6019-6028.

Kirchhausen, T., Macia, E. and Pelish, H. E. (2008). Use of dynasore, the small molecule inhibitor of dynamin, in the regulation of endocytosis. Methods Enzymol. 438, 77-97.

Klingauf, J., Kavalali, E. T. and Tsien, R. W. (1998). Kinetics and regulation of fast endocytosis at hippocampal synapses. Nature 394, 581-585.

Koenig, J. H. and Ikeda, K. (1989). Disappearance and reformation of synaptic vesicle membrane upon transmitter release observed under reversible blockage of membrane retrieval. J. Neurosci. 9, 3844-3860.

Koenig, J. H. and Ikeda, K. (1996). Synaptic vesicles have two distinct recycling pathways. J. Cell Biol. 135, 797-808.

Lee, S. Y., Voronov, S., Letinic, K., Nairn, A. C., Di Paolo, G. and De Camilli, P. (2005). Regulation of the interaction between PIPKI gamma and talin by prolinedirected protein kinases. J. Cell Biol. 168, 789-799.

Macia, E., Ehrlich, M., Massol, R., Boucrot, E., Brunner, C. and Kirchhausen, T. (2006). Dynasore, a cell-permeable inhibitor of dynamin. Dev. Cell 10, 839-850.

Mani, M., Lee, S. Y., Lucast, L., Cremona, O., Di Paolo, G., De Camilli, P. and Ryan, T. A. (2007). The dual phosphatase activity of synaptojanin 1 is required for both efficient synaptic vesicle endocytosis and reavailability at nerve terminals. Neuron 56, 1004-1018.

Marks, B., Stowell, M. H., Vallis, Y., Mills, I. G., Gibson, A., Hopkins, C. R. and McMahon, H. T. (2001). GTPase activity of dynamin and resulting conformation change are essential for endocytosis. Nature 410, 231-235.

Meijering, E., Jacob, M., Sarria, J. C., Steiner, P., Hirling, H. and Unser, M. (2004). Design and validation of a tool for neurite tracing and analysis in fluorescence microscopy images. Cytometry A 58, 167-176.

Miller, T. M. and Heuser, J. E. (1984). Endocytosis of synaptic vesicle membrane at the frog neuromuscular junction. J. Cell Biol. 98, 695-689.

Mozhayeva, M. G., Sara, Y., Liu, X. and Kavalali, E. T. (2002). Development of vesicle pools during maturation of hippocampal synapses. $J$. Neurosci. 22, 654-665.

Newton, A. J., Kirchhausen, T. and Murthy, V. N. (2006). Inhibition of dynamin completely blocks compensatory synaptic vesicle endocytosis. Proc. Natl. Acad. Sci. USA 103, 17955-17960.

Perez Bay, A. E., Ibañez, L. I. and Marengo, F. D. (2007). Rapid recovery of releasable vesicles and formation of nonreleasable endosomes follow intense exocytosis in chromaffin cells. Am. J. Physiol. Cell Physiol. 293, C1509-C1522.

Praefcke, G. J. and McMahon, H. T. (2004). The dynamin superfamily: universal membrane tubulation and fission molecules? Nat. Rev. Mol. Cell Biol. 5, 133-147.

Richards, D. A., Guatimosim, C. and Betz, W. J. (2000). Two endocytic recycling routes selectively fill two vesicle pools in frog motor nerve terminals. Neuron 27, 551-559.

Sternberg, S. R. (1983). Biomedical image processing. Computer 16, 22-34.

Takei, K., Mundigl, O., Daniell, L. and De Camilli, P. (1996). The synaptic vesicle cycle: a single vesicle budding step involving clathrin and dynamin. J. Cell Biol. 133, $1237-1250$.

Teng, H. and Wilkinson, R. S. (2000). Clathrin-mediated endocytosis near active zones in snake motor boutons. J. Neurosci. 20, 7986-7993.

Valtorta, F., Meldolesi, J. and Fesce, R. (2001). Synaptic vesicles: is kissing a matter of competence? Trends Cell Biol. 11, 324-328.

Wu, W. and Wu, L. G. (2007). Rapid bulk endocytosis and its kinetics of fission pore closure at a central synapse. Proc. Natl. Acad. Sci. USA 104, 1023410239 .

Wu, X. S., McNeil, B. D., Xu, J., Fan, J., Xue, L., Melicoff, E., Adachi, R., Bai, L. and Wu, L. G. (2009). $\mathrm{Ca}^{2+}$ and calmodulin initiate all forms of endocytosis during depolarization at a nerve terminal. J. Neurosci. 12, 1003-1010.

Zhang, Q., Li, Y. and Tsien, R. W. (2009). The dynamic control of kiss-and-run and vesicular reuse probed with single nanoparticles. Science 323, 1448-1453. 